3

4 5

6

7

\title{
Through thick and thin: changes in creativity during the first lockdown of the Covid-19 pandemic.
}

Alizée Lopez-Persem ${ }^{1 *}$, Théophile Bieth ${ }^{1,2 *}$, Stella Guiet ${ }^{1}$, Marcela Ovando-Tellez ${ }^{1}$, Emmanuelle Volle ${ }^{1}$

Affiliations :

1. FrontLab, Sorbonne Université, Institut du Cerveau - Paris Brain Institute - ICM, Inserm, CNRS, AP-HP, Hôpital de la Pitié Salpêtrière, Paris, France.

2. Neurology department, Hôpital de la Pitié Salpêtrière, AP-HP, F-75013, Paris, France

Corresponding authors: lopez.alizee@gmail.com, emmavolle@gmail.com

* Authors who contributed equally.

Acronyme: ConfiCrea

Running title: Creativity during the first lockdown of the Covid-19 pandemic 


\section{Abstract}

24 COVID-19 took us by surprise. We all had to face a new situation never encountered before and find new solutions to the problems it generated, either related to the disease or the lockdown's consequences. The lockdown and pandemic crisis caused new issues and placed us in an entirely new context, changing our way of life, work time and conditions, and habits. Coping with such an unprecedented situation may have stimulated creativity. However, the situation also restricted our liberties and wellbeing and triggered health or psychological difficulties. Worrying, concerns, challenging conditions of confinement may have hampered creativity or its expression. Hence, wellbeing factors related to affective experience, living conditions, social interactions, as well as workload or available free time, may have impacted creativity during the lockdown. We carried out an online survey based on a self-administered questionnaire to examine whether the first lockdown period related to the COVID-19 pandemic (spring 2020) was associated with creativity changes and explore the role of several factors in these changes. We measured self-reported creativity changes using two approaches: changes in creative self-efficacy and creative activities and achievements. We related them to several variables estimating time availability, conditions of confinement, social interactions, and affective experience of the situation. Despite a global negative subjective experience of the situation, individuals who participated in our survey $(n=380)$ reported that they were on average more creative during the lockdown than before and engaged in more creative activities. The converging results from self-perceived and activitybased measures showed that this positive change could be linked with more time availability, feeling more motivated or inspired, or the need to solve a problem. However, when negative changes in creativity were experienced, they were instead related to negative affective experiences, including stress and anxiety, a low mood, a feeling of pressure, or a lack of resources or opportunities. This study helps to document what happened during the first lockdown period in France regarding aspects of creativity, showing some positive outcomes of the situation despite its negative consequences, and providing cues about the key factors that stimulated or, on the contrary, blocked creativity. 


\section{Introduction}

The context of the COVID-19 pandemic has led to the implementation of unprecedented restrictive measures in society. From March 16 to May 11, 2020, 67 million French people entered the first strict lockdown with stay-at-home orders, which dramatically changed our daily lives and wellbeing. Many countries applied (and still apply) similar measures to limit the spread of the virus. These constraints imply a restriction of movement, the need to adapt working methods (remote working, partial unemployment), a modification of daily life within households (e.g., management of children, protection of vulnerable people, living conditions), and a decreased wellbeing (linked to health issues, restrictions of activities and social interactions, or economic consequences) with elements of distress, loneliness, and anxiety $^{1-5}$. Paradoxically, during this period, general and social media have reported that individuals and businesses seemed to show great adaptability to face the situation by finding innovative solutions as well as creative behaviors.

Creativity is defined in science as the ability to produce something that is both original and appropriate ${ }^{6}$. Creative abilities are involved in many human activities, from solving everyday problems (little-c) to the great discoveries of our civilization (Big-C). Creativity is a key mental capacity to cope with change, invent and innovate, and face the challenges of our society. The situation related to the COVID-19 and its consequences on our daily life and working conditions are at the forefront of the current challenges we had and still have to cope with. Understanding the conditions that foster (or hinder) our creativity is essential, and the COVID-19 situation provides a unique opportunity to study some of these factors. Hence, the current study aimed to 1) explore how this unprecedented context has changed the creative behavior of individuals and 2) try to understand the factors influencing this change. It also helps to document this unprecedented period from a new perspective and tell another aspect of collective history: individuals' creativity.

According to the multidimensional approach to creativity ${ }^{7}$, creativity relies on cognitive factors (our mental capacities), individual personality, and motivation. It is influenced by emotions (e.g., mood) and factors related to our environment (living conditions, social, cultural, and professional context). Cognitive factors underlying creativity depend on complex cognitive operations that include control and spontaneous processes. Control processes allow us to respond to the environment's constraints and direct behaviors towards a specific goal. They include, for instance, inhibiting common ideas or manipulating concepts $^{8-11}$. Spontaneous processes are based in part on semantic associative mechanisms ${ }^{12-}$ 14, and allow idea generation. They usually benefit from a release of constraints from the environment. These two categories of cognitive processes interact, and their relative involvement depends on the context and the task in which individuals are engaged ${ }^{15-20}$.

Emotional, contextual, and environmental factors have a critical impact on creative mental operations or their implementation as a creative behavior6. A series of studies have highlighted the strong relationships between affective states and creativity and showed that 
creative thinking tasks are mood-sensitive. Positive mood (such as joy) is often reported as facilitating creativity, and negative mood (such as stress, anxiety) as hindering creativity. However, whether positive or negative moods facilitate or inhibit creativity is still debated in the literature and may depend on contextual factors ${ }^{21-23}$. Individual motivation, especially intrinsic motivation, is an essential component of creative behavior ${ }^{24-29}$ and drives involvement, intensity, and perseverance in activities. Finally, creative activities and achievements are influenced by our environment, at home or in the workspace, and by the standards, needs, and values of the society?

The situation related to COVID-19 likely has a major impact on many if not all the creativity dimensions or factors described above, by affecting our emotions, motivations, and wellbeing, modifying our environment, our lifestyle, and availability, but also by modifying the standards and incentives of our society during this period, opening a new framework of thought ${ }^{30,31}$. Several studies reported how the pandemic and lockdown had increased psychological distress, mood disorders, loneliness, and anxiety ${ }^{1-5}$, with a potential negative impact on creativity. Nevertheless, the few existing scientific studies that explored creativity during the COVID-19 pandemic have indeed suggested that the lockdown period facilitated everyday creativity ${ }^{32,33}$ or that creative abilities could help people dealing with the situation and improve their wellbeing ${ }^{3,34,35}$. However, those studies did not assess how creativity changes related to environmental, contextual, or emotional changes.

The current study aimed at exploring how the lockdown and context related to COVID-19 had positively or negatively impacted creativity and identifying the potential factors linked to these changes. Our working hypotheses were that the lockdown could have stimulated creativity for at least two reasons. First, the confinement increased the availability of time and mind by reducing our usual daily outdoor activities and, in some cases, workload. More free time provides an opportunity to engage in new activities, produce more thoughts and ideas. Second, the new situation created a need or drive, pushing the individuals to adapt to continue their usual activities. Facing and solving the new problems may have led individuals to propose original solutions. However, other factors triggered by the situation could have blocked creativity. For instance, unfavorable living conditions, including a shrinking of personal space, or intense workload, can limit creativity or its expression. Also, the situation may have caused negative subjective experience and distress, with stress and anxiety, a feeling of pressure, a lower mood, which can alter creativity. Last, because the restrictive measures related to the COVID-19 targeted social interactions tremendously and unexpectedly and creativity is also influenced by the social context $\mathrm{t}^{25,28}$, we hypothesized that social distancing could also have harmed creativity.

Thus, the specific objectives of this study were to assess whether the first lockdown in France stimulated or altered everyday creativity, and to explore the role of the hypothesized factors on these changes, i.e., free time, subjective experience of the situation, social interactions, living conditions. We carried out an online survey based on a self-administered questionnaire to estimate the impact of the first lockdown on two aspects of creativity: selfperceived creativity changes and changes in creative activities and achievements. We 
collected information related to our main tested factors by a series of independent questions targeting the individuals' everyday conditions during the lockdown and the reasons why they engaged or not in creative activities.

\section{Results}

\section{Demographics and lockdown situation}

Participants completed the survey between May $27^{\text {th }}$ and August $1^{\text {st }}$ of the year 2020, just after the end of the French first lockdown period. All questions were referred to the lockdown period, that was, in mainland France, from March $16^{\text {th }}$ to May $11^{\text {th }}$. Data from 380 participants were included in the analyses (281 females; mean age 43.16 years, age ranging from 18 to 84 years).

The first part of the survey was designed to collect information about the confinement circumstances of the participants. Overall, the majority of participants were confined in France $(77 \%)$, at home $(85 \%)$, in urban areas (50\%). 63\% had access to private or large public outdoor spaces, $60 \%$ were confined with one or more individuals, and $87 \%$ declared not having encountered a severe problem during the lockdown. They were working remotely for $54 \%$ of them. $83 \%$ of the respondents had a professional activity not related to the fight against the pandemic. All demographic details are provided in Table 1 and Supplementary Table S1.

\section{Living conditions and subjective experience of the lockdown} situation

In the survey, participants were asked subjective and objective questions to gather information about their lockdown experience. These items aimed at estimating their environmental conditions (available space per cohabitant, i.e., number of rooms per inhabitant; feeling of a change in physical constraints), social relationships (change in the number of social interactions; feeling of a change in loneliness), available time (number of working hours per week; feeling of a change in time availability), and subjective affective changes (feeling of a change in mood, motivation, anxiety or stress, and pressure) (see methods for more details). Those ten measures were used to assess the living conditions and subjective experience of the lockdown situation.

As expected, on average and in terms of subjective experience, our sample felt more physically constrained (mean $\left.=0.33+/-0.08, \mathrm{t}(379)=4.16, \mathrm{p}=4.10^{-5}\right)$, more lonely (mean $=0.32+/-$ $\left.0.07, \mathrm{t}(379)=4.69, \mathrm{p}=4.10^{-6}\right)$, and with more free time (mean=0.6+/-0.07, $\left.\mathrm{t}(379)=8.82, \mathrm{p}=4.10^{-17}\right)$. In terms of affective changes, they felt more anxious or stressed (mean $=0.32+/-0.08$, $\left.\mathrm{t}(379)=3.96, \mathrm{p}=9.10^{-5}\right)$, and had a poorer $\operatorname{mood}(\operatorname{mean}=-0.18+/-0.07, \mathrm{t}(379)=-2.39, \mathrm{p}=0.02)$. On 
average, they did not feel significantly more or less motivated (mean $=0.12+/-0.09, t(379)=1.39$, $\mathrm{p}=0.17$ ), nor experienced more (or less) psychological pressure (mean $=0.09+/-0.09, \mathrm{t}(379)=1$, $\mathrm{p}=0.32$ ).

Within-factor measures were consistent. Indeed, the subjective report of change in physical constraints was correlated with the number of rooms per inhabitant (mean=1.19+/-0.03, $\mathrm{r}=0.10, \mathrm{p}=0.049$ ), the subjective report of change in loneliness was correlated with the quantitative change in social interactions (mean $=-0.22+/-0.07, \mathrm{t}(379)=-3.31, \mathrm{p}=1.10^{-3} \mathrm{r}=0.18$, $\mathrm{p}=5.10^{-3}$ ). The subjective report of change in free time was correlated with the number of working hour per week (20\% worked more than 42 hours/week, 19\% between 36 and 42 hours/week, 15\% between 29 and 35 hours/week, 13\% between 22 and 28 hours/week, 14\% between 15 and 21 hours/week, 9\% between 8 and 14 hours/week, 10\% less than 7 hours/week, $\mathrm{r}=0.53, \mathrm{p}=6.10^{-24}$ ). Additionally, affective changes in mood, motivation, anxiety or stress, and pressure were all correlated to each other (all $\left.\mathrm{p}<8.10^{-11}\right)$.

\section{Subjective creativity change during the lockdown}

\section{Measures of creativity}

When prompted to subjectively report how much they think their creativity changed during the lockdown (subjective creativity change - SCC, rating scale from -50 to 50), the participants declared on average to have been more creative during the lockdown period (mean=8.08+/0.98, $\left.\mathrm{t}(379)=8.26, \mathrm{p}=2.10^{-15}\right)$ (Figure $1 \mathrm{~A}$ ).

Additionally, at the end of the survey, participants were asked to freely report the five most creative productions they carried out during the lockdown. Those productions' creativity was evaluated by four different raters, all experts in creativity research, on a Likert scale (05). The inter-class correlation was 0.95 , and the ratings from the four raters were averaged for each production. We then computed a global score of creativity during the lockdown by summing the average ratings of all productions for each subject, yielding a rating score (RS) ranging from 0 to 25 . RS mean was $7.74+/-0.21$ across the 286 participants who responded to that question.

Creative personality traits were also assessed using the BFI-openness (BFI-O) questionnaire validated in French ${ }^{36}$. The average score of our sample was 3.68+/-0.03.

The BFI-O scores, RS and SCC were all significantly pairwise correlated $(\mathrm{r}(\mathrm{BFI}-\mathrm{O}-\mathrm{RS})=0.46$, $\left.\mathrm{p}=2.10^{-16}, \mathrm{r}(\mathrm{BFI}-\mathrm{O}-\mathrm{SCC})=0.21, \mathrm{p}=3.10^{-2}, \mathrm{r}(\mathrm{SCC}-\mathrm{RS})=0.15, \mathrm{p}=9.10^{-3}\right)$. Hence, as the RS might reflect both the creative personality traits and creativity changes during the lockdown, we tested whether BFI-O scores mediated the correlation between SCC and RS. The mediation analysis revealed that the correlation between SCC and RS was mediated by the BFI-O scores, as we observed a loss of significance of the direct path when including the mediator effect (linear regression of SCC against RS (without the mediator): $\boldsymbol{\beta}_{\mathrm{scC}-\mathrm{RS}}=0.68, \mathrm{p}=9.10^{-3}$; linear regression of SCC against RS and BFI-O (the mediator): $\boldsymbol{\beta}^{*}{ }_{\text {SCC-Rs }}=0.37, p=0.2$ ). The difference between $\boldsymbol{\beta}_{\text {SCC-RS }}$ and $\boldsymbol{\beta}^{*}$ SCC-RS was confirmed using bootstrapping (confidence interval=[0.01 
0.62]). Since our main aim was to assess the creativity change related to the lockdown, we decided to use the SCC score as our main variable of interest, as RS seems to reflect more the creative personality traits than the change in creativity during the lockdown period, and because we did not have a baseline measurement of creativity.

\section{Relations between SCC and subjective experience during the lockdown}

A

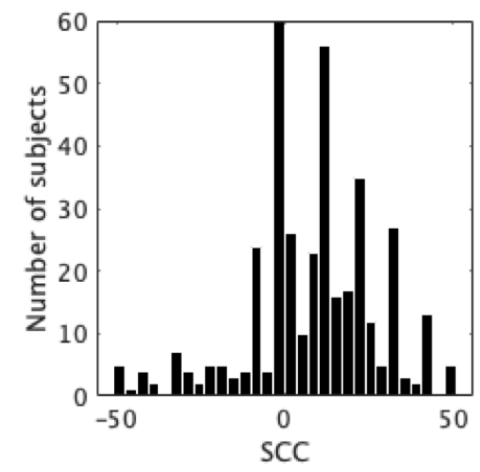

C

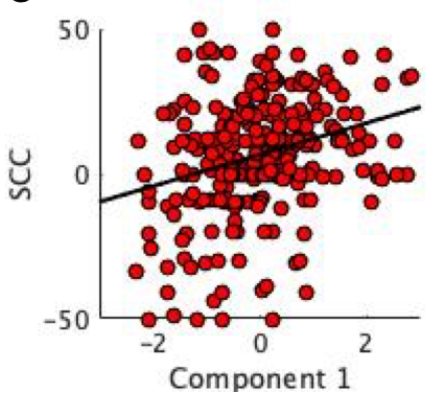

B

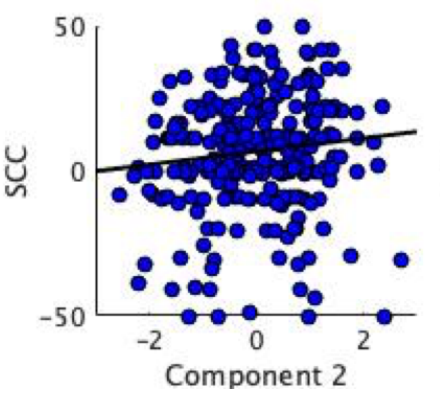

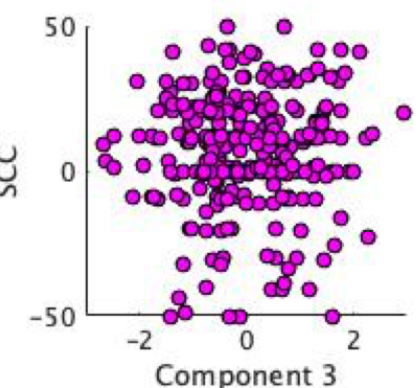

Figure 1. Subjective creativity change (SCC) and subjective experience of the lockdown. A. Histogram of SCC scores. B. Correlation matrix between measures assessing the living conditions and subjective experience of the lockdown situation. Stars indicate $\mathrm{p}<0.05$. Cold to hot colors represent the Pearson correlation coefficient ( $\mathrm{r}$ ). $\mathrm{R}$ indicates that the measure's sign was reversed to get positive values as positive changes (improvement) for all variables. Colored squares group measures clustering on the three principal components (red: Component 1, blue: Component 2, magenta: Component 3). C. SCC as a function of participant's component loadings. One dot represents one participant, and bold lines indicate that the correlation between the principal component and SCC was significant (Pearson correlation, $\mathrm{p}<0.05$ ).

We explored the link between SCC and the variables reflecting the living conditions and subjective experience of the lockdown situation. To reduce our set of variables into a smaller set of dimensions, we conducted a principal component analysis on the ten variables of interest using the available complete data from 287 participants. The Kaiser-Meyer-Olkin measure was 0.755 , above the acceptable limit of 0.5 . Three factors had eigenvalues over one and, in combination, explained $53.1 \%$ of the variance. Figure $1 \mathrm{~B}$ shows the correlation matrix 
between variables, and Table 2 shows the components loadings after rotation. The variables that cluster on the same component suggest that component 1 represents affective changes during the lockdown, component 2 represents changes in the available time, and component 3 interactions with other people.

We searched for correlations between the participant's components loadings and SCC. SCC correlated significantly with component 1 representing affective changes during lockdown $\left(\mathrm{r}=0.28, \mathrm{p}=1.10^{-6}\right)$ and with component 2 representing changes in time available $(\mathrm{r}=0.12$, $\mathrm{p}=0.045)$, but not with component 3 representing interactions with other people $(\mathrm{r}=0.04$, $\mathrm{p}=0.52$ ) (Figure 1C). Individual correlations of each variable and SCC are provided in Supplementary Table S2. These results indicate that two main factors were associated with subjective creativity changes during the lockdown period: affective changes and change in the available time. Restrictions in social interactions were not significantly associated with creativity changes.

As creativity could help emotionally cope with difficult situations, we explored whether creative personality traits could have impacted the subjective and affective experience of the lockdown, which influenced creativity changes. We tested for a mediation effect of component 1 (representing affective changes during lockdown) on the relationship between BFI-O and SCC. The results showed a significant partial mediation with a decrease in the direct path when including the mediator effect (linear regression of SCC against BFI-O (without the mediator): $\boldsymbol{\beta}$ scC-BFI-O $=0.62, \mathrm{p}=3.10^{-5}$; linear regression of SCC against PC1 and BFIO: $\boldsymbol{\beta}^{*}$ SCC-BFI-O $=0.38, p=0.02$ ). The difference between $\boldsymbol{\beta}_{\text {sCC-BFI-O }}$ and $\boldsymbol{\beta}^{*}$ SCC-BFI-O was confirmed using bootstrapping (confidence interval=[0.08 0.44]). Hence, individuals with higher openness may have felt more creative because they managed to have a more positive affective experience during the lockdown. The same mediation analysis conducted with the second component loadings (time available) did not reveal a significant mediation effect (confidence interval=[0 0.33$])$.

Regarding demographic and other categorical factors, there was no significant effect of gender $(\mathrm{F}(1,378)=0.01, \mathrm{p}=0.93)$, age $(\mathrm{r}=-0.02, \mathrm{p}=0.69)$, education (rho=0.04, $\mathrm{p}=0.44)$, socioprofessional category $(\mathrm{F}(8,350)=1.45, \mathrm{p}=0.17)$, socio-professional domain $(\mathrm{F}(19,339)=0.64$, $\mathrm{p}=0.88)$, or residential area $(\mathrm{F}(2,377)=0.43, \mathrm{p}=0.65)$ on SCC (see Table 1$)$. Being at home $(\mathrm{F}(1$, $378)=0, p=0.99)$, having a job related to COVID-19 $(\mathrm{F}(1,378)=0, \mathrm{p}=0.99)$, or working remotely $(\mathrm{F}(1,378)=0.56, \mathrm{p}=0.46)$ had also no significant association with SCC.

\section{Change in creative activities}

In the survey, we qualitatively and quantitatively assessed the creativity change experienced during the lockdown. In total, 343 participants were presented with 28 activities (among them, 37 participants completed an older version of the questionnaire that included additional questions not considered here). All activities are reported in Supplementary Table S3. For each of them, participants were first asked to indicate whether they had performed 

they did it during the lockdown and how often (more or less than before), for which reasons (various reasons were proposed for negative and positive frequency changes), and how they valorized it (showed it to co-confinee, on social media, sold it, or reached other achievements). For each activity that was less performed during the confinement than before, the participants were asked whether they thought more or less about it during the lockdown.

\section{Activities}

We identified activities that were relevant at the participant level to further estimate a lockdown-related change. On average, participants engaged in 8.38+/-0.25 activities (out of the 28 proposed) during the previous five years (including the lockdown period). Three participants did not engage in any activity, and four participants engaged in more than 20 activities. All the activities were performed at least by $9.9 \%$ of the participants during the lockdown (Figure 2). The activities of our list were consistent with the top-productions that the participants freely reported (see 'Top-production' section below).

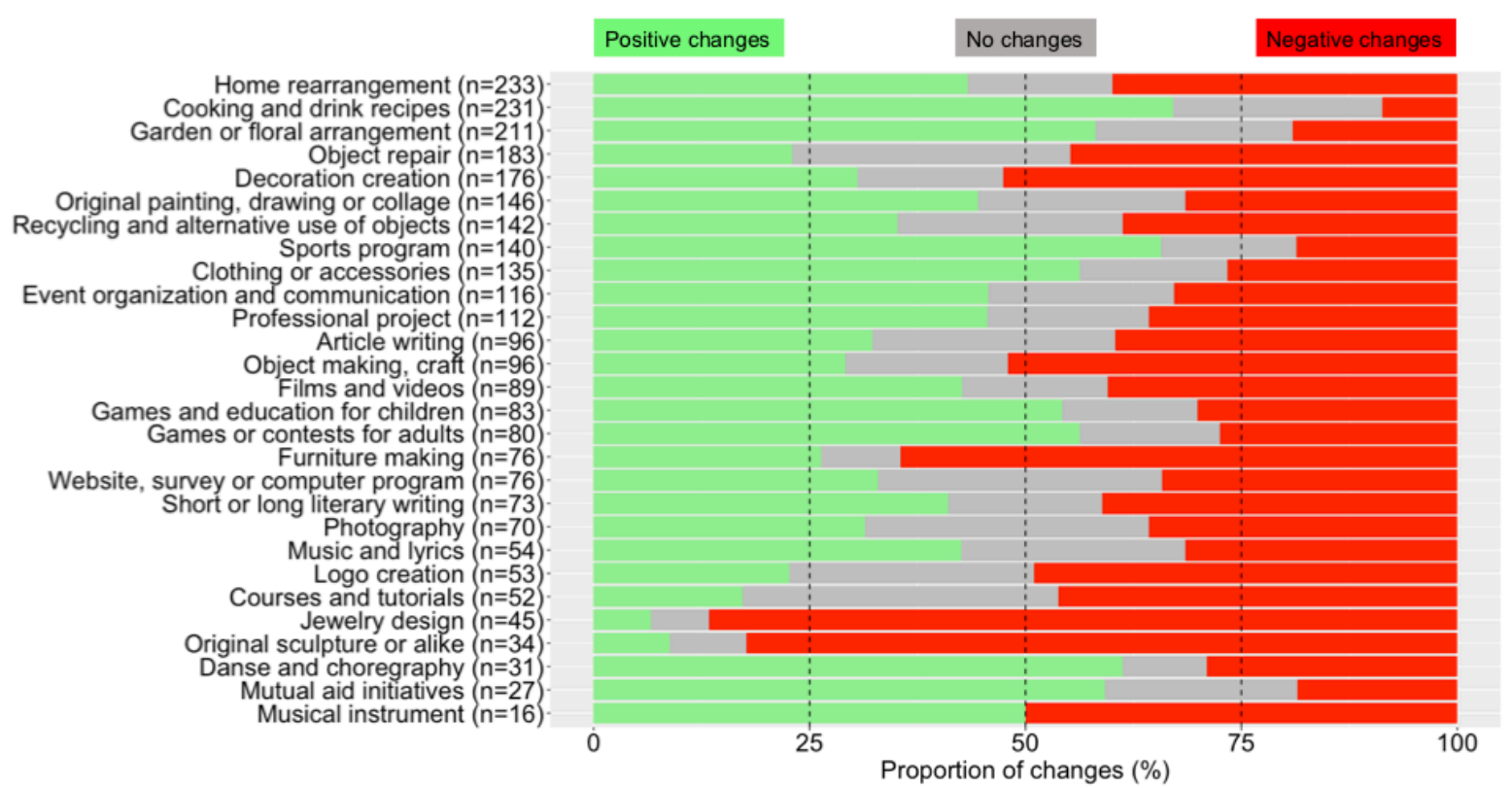

Figure 2. Frequencies and changes in activities. Proportions of changes across subjects regarding each of the 28 activities on the list for positive changes (in green), negative changes (in red), or no changes (in grey). Changes refer to a difference reported by each subject between the five last years preceding the lockdown and the lockdown period. Each activity is named by its English-translated quick name (see Table S4) and is associated with the number of subjects who answered this question (i.e., subjects who did the activity during the last five years, including the lockdown period). Activities are sorted in descending order based on the number of subjects involved in this activity.

We also quantified the changes that occurred during the lockdown for each activity performed in the last five years (Figure 2). Among the activities performed during the last 
five years, the five activities with the highest increase in frequency during the lockdown across participants were 'Cooking and drink recipes' (67.1\% of the participants, $n=233$ ),

295 'Sports program' (65.7\%, n=140), 'Dance and choreography' (61.3\%, n=31), 'Mutual aid 296 initiatives' (59.3\%, n=27) and 'Garden or floral arrangement' (58.1\%, n=211). Activities with 297 the deepest decrease in frequency during the lockdown were 'Jewelry design' ( $86.7 \%, n=45)$, 298 'Original sculpture or alike' (82.4\%, n=34), 'Furniture making' (64.5\%, n=75), ‘Decoration 299 creation' (52.5\%, $\mathrm{n}=176)$, and 'Object making, craft' $(52.1 \%, \mathrm{n}=96)$.

\section{Quantitative changes in activities during the lockdown period}

301 To quantify the overall changes in performing creative activities during the lockdown (based 302 on our list of 28 activities), we computed the average frequency of change across activities 303 for each subject (Figure $3 \mathrm{~A}$ ). On average, $40.3+/-1.5 \%$ of the activities performed by the 304 participants during the last five years were carried out more frequently during the lockdown, 305 and additionally, $5.2+/-0.7 \%$ of the activities were new ones. Conversely, $20.2+/-1.3 \%$ were 306 carried out at the same frequency, $2.7+/-0.4 \%$ less frequently, and $20+/-1.2 \%$ were not performed at all during the lockdown. Another $11.8+/-0.2 \%$ of the activities were not 308 performed, but the participants thought about it during the lockdown period. The 309 proportions of activities that were more (positive changes), less (negative changes), and 310 equally (no change) performed during the lockdown differed significantly $(F(2,678)=49$, $311 \mathrm{p}=2.10^{-19}$ with Greenhouse-Geisser correction; Figure 3B). Post-hoc Tukey tests revealed 312 significant differences between all pairwise comparisons $\left(\mathrm{p}_{\mathrm{corr}}<10^{-7}\right)$.

313 Importantly, the mean frequency of change across activities was significantly correlated with $314 \operatorname{SCC}\left(\mathrm{n}=331, \mathrm{rho}=0.23, \mathrm{p}=3.10^{-5}\right.$; Figure $\left.3 \mathrm{C}\right)$. 
A

B
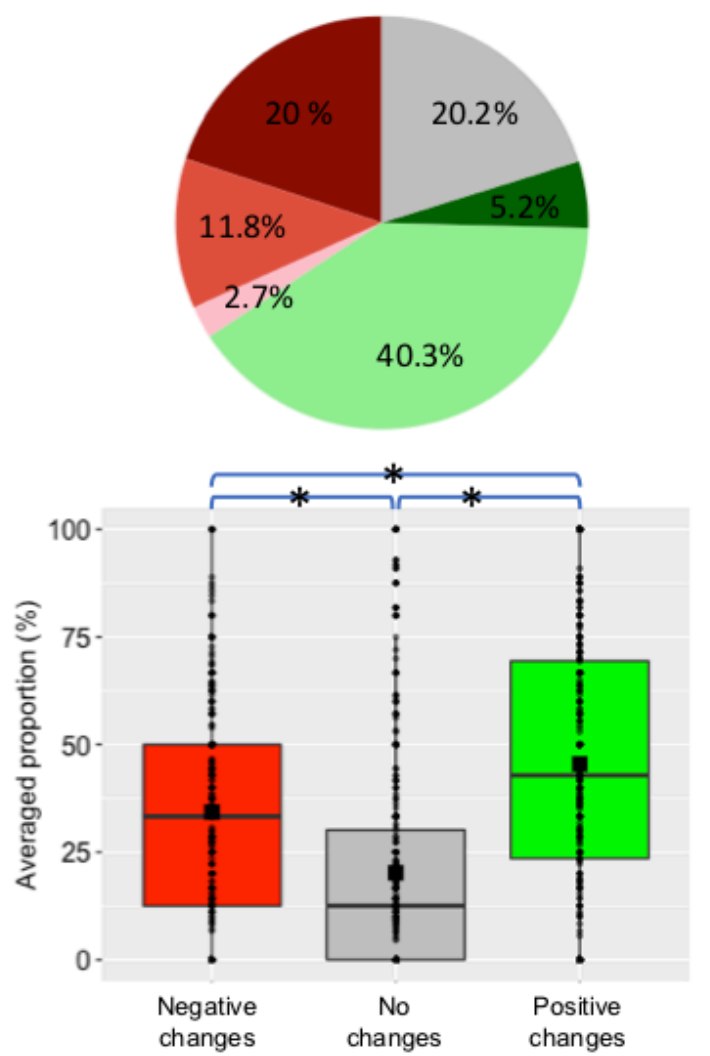

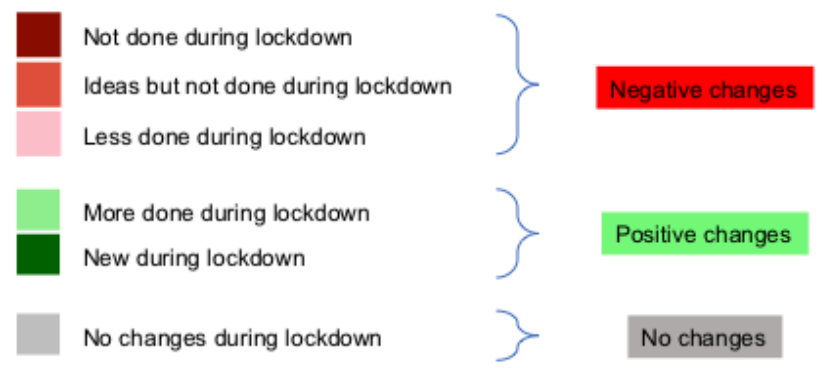

C

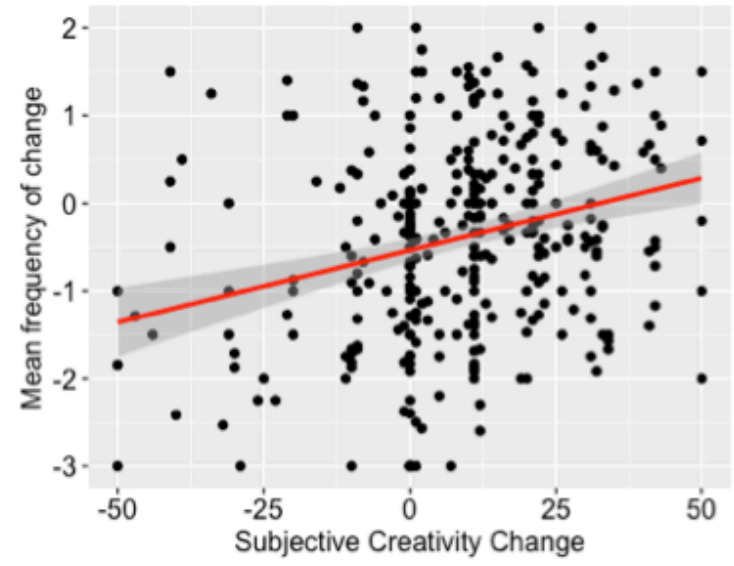

Figure 3. Quantitative changes in performing creative activities during the lockdown period. A. Averaged proportions of changes across participants in performing activities. We show the activities with negative changes, positive changes, and no changes separately. The activities with negative changes were not done during the lockdown (dark red), were not done, but participants had ideas to do it (light red) or were done less frequently than before the lockdown (pink). The activities with positive changes were done more frequently (light green) or were new (dark green) during the lockdown. The activities with no changes were done as frequently (gray) as before the lockdown. $\mathbf{B}$. Averaged proportion of changes across participants for negative changes (red), no changes (gray), and positive changes (green) during the lockdown period compared to the five last years. Each dot represents a participant, color boxes represent the upper and lower quartiles, and squares indicate the mean. Stars indicate post hoc tests with a $p_{c o r r}<0.05$. C. Participant's SCC as a function of the averaged frequency score of change (a dot per participant). The red line indicates a significant correlation between SCC and the mean frequency score of change (Pearson correlation, $\mathrm{p}<0.05$ ).

\section{Reasons and motives}

To examine why each activity was more or less frequently performed during the lockdown than before, we analyzed the reasons provided by the participants for positive and negative changes separately (Figures $4 \mathrm{~A}$ and $4 \mathrm{C}$, respectively). Note that they could select several reasons for each activity during the survey.

Across all activities, the frequency of the selected reasons for positive changes significantly differed $\left(F(6,1722)=152\right.$, $p=2.10^{-98}$ with Greenhouse-Geisser correction; Figure 4B). The most frequently selected reasons for positive changes were: 1 ) having more free time ('More time,' $60+/-2.3 \%$ of the activities carried out by each subject); free time significantly differed from each of the other reasons ( $p_{\text {corr }}<0.05$ for all posthoc tests); 2 ) being inspired by the lockdown 
situation ('Inspired,' 21.3+/-1.7\%); and 3) having to solve lockdown/pandemic issues ('Problem solving,' 20.8+/-1.6\%). The frequency of those two last reasons did not statistically differ but was higher than the frequency of each of the remaining reasons ( $p_{\text {corr }}<0.05$ for all corresponding post hoc tests). Additionally, $12.3+/-1.3 \%$ of the activities performed more often than before were carried out for work ('Work related'), and $11.1+/-1.3 \%$ for other undetermined reasons ('Others'). The frequencies of these last two reasons did not significantly differ from each other but were significantly higher than the frequency of each of the remaining reasons that were to feel better ('Wellbeing') and that the conditions of confinement were favorable to this activity ('Favorable conditions') ( $\mathrm{p}_{\mathrm{corr}}<0.05$ for all posthoc tests).
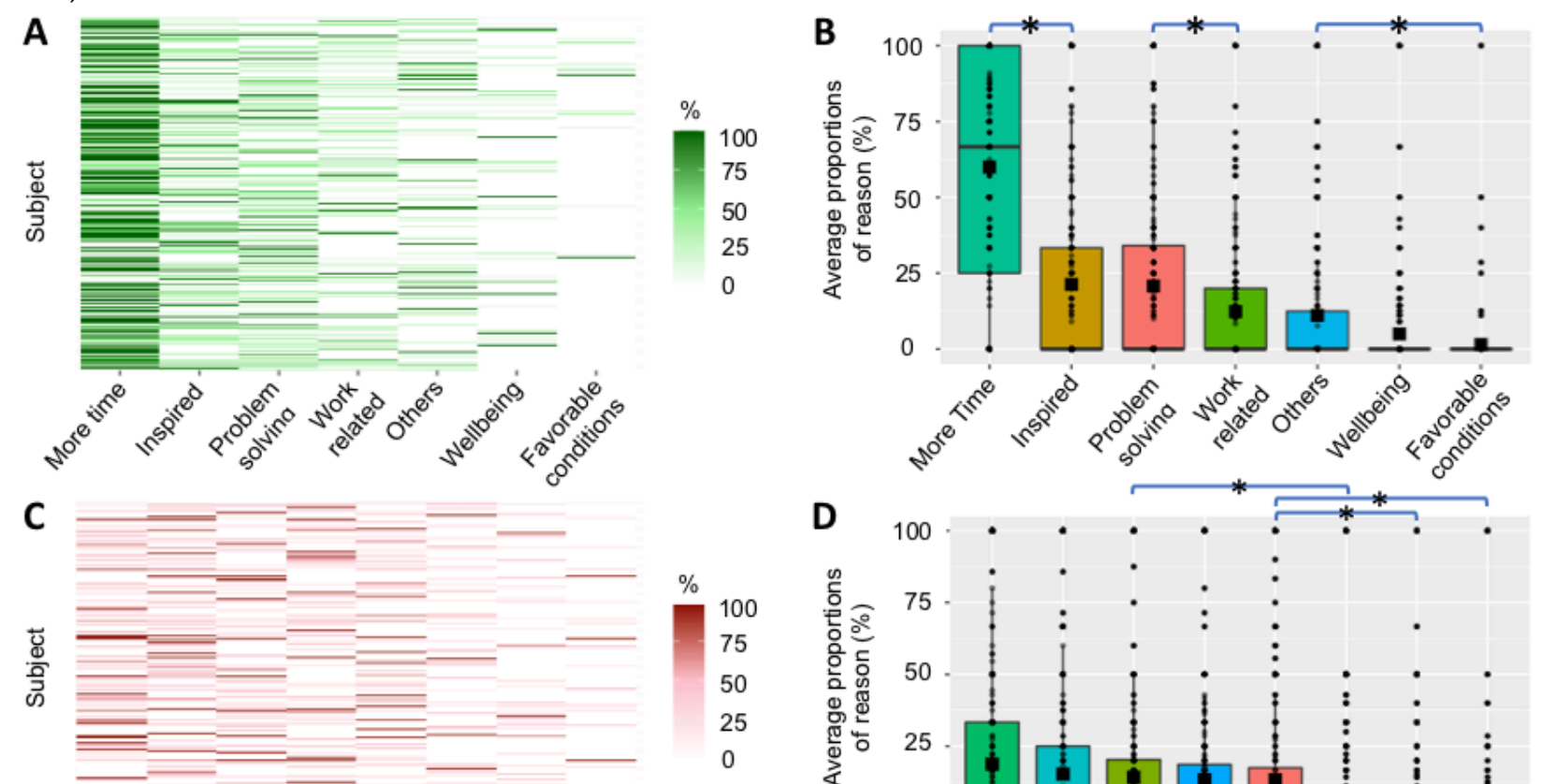

Among the reasons for negative changes, the frequency of the reported reasons significantly

Figure 4. Reported reasons for positive and negative changes in creative activities. A. Proportions of reasons for positive changes. Each row represents a participant, and reasons are sorted by decreasing average proportion across subjects. B. Boxplots of the average proportion of reasons for positive changes across subjects. Each dot represents a participant, color boxes represent the upper and lower quartiles, and squares indicate the mean. Stars indicate significant differences between proportions of selected reasons (post hoc tests with $p_{c o r r}<0.05$ ). $\mathbf{C}$ and $\mathbf{D}$ are the equivalent of $A$ and $B$, respectively, for negative changes. differed $\left(F(7,1925)=14, p=5.10^{-15}\right.$ with Greenhouse-Geisser correction; Figure 4D). The most selected reasons for carrying out an activity less frequently than before were: 1 ) having other concerns or worries ('Concerns and worries,' 18.8+/-1.7\%), 2) not having favorable conditions ('Unfavorable conditions,' 15.3+/-1.6\%), 3) not willing or not feeling like doing it ('Did not feel like it,' $14.1+/-1.6 \%)$, 4) lacking the necessary material to do it ('Lack of resources,' 13.1+/- 

main reasons did not statistically differ from each other ( $p_{\text {corr }}>0.05$ for all posthoc tests). However, the frequency of each of these reasons differed significantly from the remaining reasons that were: not having ideas for this activity ('Lack of ideas,' $3+/-0.8 \%$ ), that this activity was performed only occasionally before and was not common for the participant ('Occasionally,' 6.3+/-1.1\%), or other undetermined reasons ('Others,' 7.9+/-1.2\%) (p corr $>0.05$ for all posthoc tests).

To check the consistency of the participant's responses to the first part of the survey (global experience of the lockdown) and the second part (activity-based questions), we explored whether the activity-based reported reasons correlated with the global subjective experience of the lockdown measured in the first part of the survey. The difference between selecting 'Inspired' for positive reasons and 'Concerned and worries' or 'Did not feel like it' for negative reasons was correlated with Component 1 (reflecting affective experience) across individuals $(\mathrm{r}=0.13, \mathrm{p}=0.03)$. Additionally, we found that the difference between selecting 'More time' for positive reasons and 'No time' for negative reasons was correlated with Component 2 (reflecting more free time) across individuals ( $\mathrm{r}=0.51, \mathrm{p}=2.10^{-19}$ ) (See Methods and Supplementary Figure S1).

384

\section{Obstacles}

For each activity carried out more frequently or as often as before the lockdown, participants were asked how many obstacles they had to overcome to conduct this activity (an obstacle score was computed based on the average of ratings provided across performed activities for each subject, using a rating scale from 0 to 100). On average, they reported a low amount of obstacles to overcome (mean: $15.44+/-0.79$ ). The mean obstacle score was not significantly correlated to SCC $(\mathrm{r}=-0.04, \mathrm{p}=0.49, \mathrm{n}=331)$. However, using a polynomial fit of second-order, we identified a quadratic relationship between those two measures $\left(\boldsymbol{\beta}_{\text {quadr }}=4.10^{-3}, \mathrm{p}=5.10^{-3}\right)$ (Supplementary Figure S2), suggesting that the amount of encountered obstacle was high for individuals experiencing a large negative or positive SCC.

\section{Creative achievements}

In this survey, we estimated, for each participant, the level of creative achievements for the activities performed during the lockdown by adapting items of an achievement questionnaire (ICAA, part $2^{37}$ ) (Figure 5; see Supplementary Table S4 for details). For the activities carried out more frequently or as often during the lockdown as before, we asked the participants to report how they shared their activities to other people, published something, were recognized by other groups or in the media, won prizes, or sold their work. The participants reported that for $53.98+/-1.80 \%$ of the activities they carried out, they shared the result with family, friends, or colleagues, and $16.96+/-1.47 \%$ were shared with no one. For $11.08+/-1.09 \%$ of the performed activities, the results were communicated to the participant's remote social network. Among higher achievements, the participants reported that the result 
of their activity was noticed outside of their usual network for $5.89+/-0.81 \%$ of their activities, published for $4.28+/-0.66 \%$, or mentioned in the media for $1.27+/-0.43 \%$. Other achievements represented less than $1 \%$ of the activities each.

Importantly, based on the level of achievement reported by the participants, we computed a creative achievement score per participant (see Methods), and we found that it was significantly correlated with SCC $\left(\mathrm{n}=330, \mathrm{rho}=0.16, \mathrm{p}=4.10^{-3}\right)$.

\section{A \\ A}
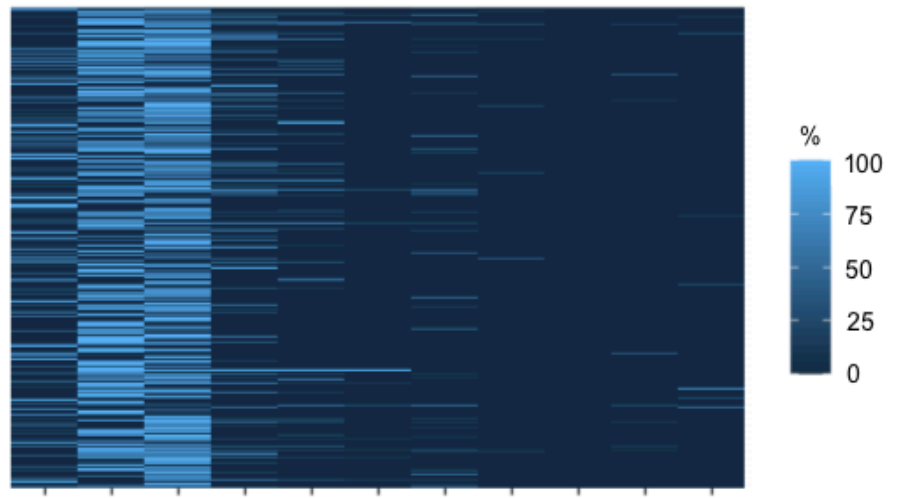

B 25
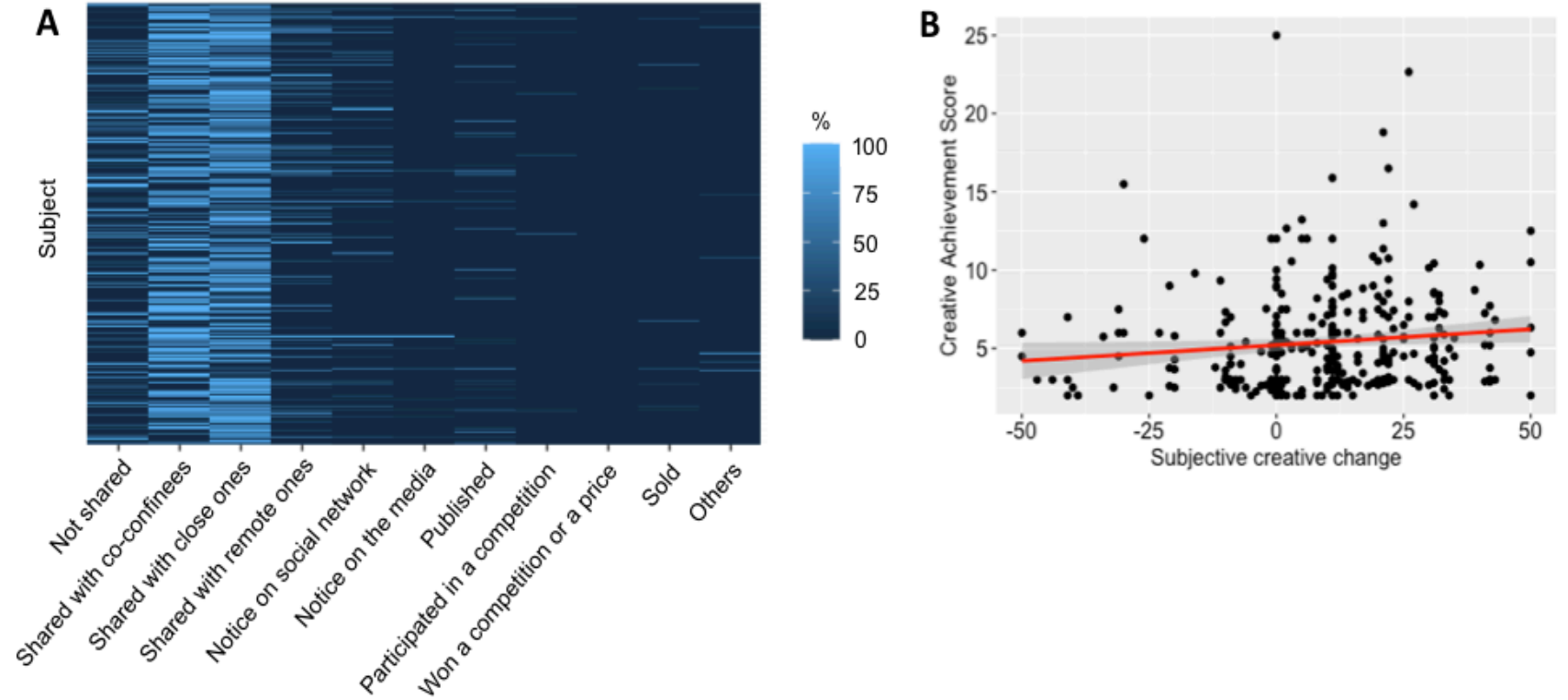

Figure 5. Creative Achievements. A. Proportion of the selected levels of creative achievement averaged across activities for each subject. B. Individual SCC as a function of individual creative achievement score. The red line indicates a significant correlation between SCC and the creative achievement score (Pearson correlation, $\mathrm{p}<0.05$ ).

\section{Top-productions}

At the end of the survey, participants were asked to freely report their most creative productions (up to five) during the lockdown. To check the validity of our list of activities, we examined whether each of the 1091 reported top-productions corresponded to an activity included in our list. We found that $90 \%$ of the top-productions reported by the participants were in the list (with a mean+/-SEM RS of $2.1+/-0.03$ on a rating scale from 0 to 5). Moreover, among the $10 \%$ of the top-productions that were not referring to an activity included in our list, $83.5 \%$ had an RS lower than 2.5 (with a mean+/-SEM RS of 1.3+/-0.1). The majority of those low-rated top-productions were about 'learning something new,' 'storing/classifying,' 'reading,' and 'projects/ideas.' Among the top-productions not covered by our list, the topproductions with a score higher than 2.5 (18 productions) were about ecology ( $n=3)$, artistic projects or ideas $(n=4)$, and diverse multimedia creations $(n=3)$.

To analyze the frequency of the productions among the participants, we recoded the name of the top-productions and selected the ones with a mean RS higher than 0.5. 'Cooking and recipes' were the most frequent realizations (reported by $31 \%$ and $19 \%$ of the participants), followed by 'Writing' (25\%), 'Manufacturing' (19\%), 'Gardening' (18\%), and 'Sewing' (13\%). 
433 Using an online survey, we aimed to estimate the impact on creativity of the lockdown in

434 France due to the COVID-19 pandemic and to understand the potential factors leading to creativity changes. Our main a priori factors were the affective states, available time, personal conditions of confinement, and social isolation. Our survey used two main approaches to quantify creativity changes and their reasons: a global subjective report and an activity-based questionnaire. Participants reported that, on average, they felt more constrained, anxious or stressed, lonely, and with lower mood, but also had more free time. On average, they judged their own creativity (SCC) as increased during the lockdown period when compared to before.

Interestingly, this subjective increase in creative self-perception was positively significantly correlated with the increase in available time and negatively with the degradation of affective states. The activity-based approach showed, on average, a positive change in everyday creative activities that significantly correlated with SCC. However, the positive or negative direction of the changes varied across activities and individuals. Among activities that were performed more frequently during the lockdown, participants declared that they carried them out mainly thanks to an increase in their amount of free time. Less frequently reported reasons were being inspired by the situation or having to solve a problem related to it. Among activities that were performed less often during the lockdown, the most frequently reported reasons were: having worries and concerns, experiencing a lack of motivation, technical or resources issues, and lack of time. In sum, the subjective report of self-creativity and activity-based questionnaire provide converging results supporting an overall positive change in creativity during the lockdown period, which was mainly related to having more free time. However, the changes were heterogeneous across participants, and when negative changes in self-creativity or creative activities were reported, they were mainly related to affective factors.

\section{Creativity during the lockdown}

In this survey, we assessed several aspects of creativity and its changes during the lockdown period. Creativity changes were first estimated based on a self-report of a change as perceived by each participant (SCC). SCC revealed that participants experienced being more creative during the lockdown than the period before, which is consistent with previous studies that reported an increase in everyday creativity during the lockdown ${ }^{32,33}$. SCC correlated with the BFI-O score, which captures a basal creative personality trait ${ }^{38,39}$ and which was in the range of what has been previously observed ${ }^{40}$. The correlation between SCC and BFI-O indicates that individuals with higher openness to new experiences reported more positive self-perceived creativity changes. The link between BFI-O and SCC was linear: the 
seems at variance with Mercier and colleagues'32 results showing that participants with a lower creativity baseline experienced a larger improvement in everyday creativity during the lockdown than those with a higher baseline. Their baseline measure of creativity was assessed by adapting a past tense scale of everyday situations. This discrepancy might indicate that creativity traits (that BFI-O measures in our study) and other creativity dimensions (measured by a baseline self-perception scale in Mercier and colleagues' study) modulated everyday creativity changes during the lockdown period in different ways. Here, we also assessed creativity during the lockdown using an external rating approach of the top5 creative productions freely reported by the participants (RS). SCC correlated positively with this measure, indicating that the participants who reported a higher increase in their creativity also had higher creativity ratings of their top-productions. Interestingly, BFI-O mediated the link between SCC and RS, suggesting that creativity during the lockdown (as measured by external ratings of the participants' productions) depended on both a basal creative personality trait (BFI-O) and the subjective feeling of lockdown-related changes in creativity (SCC). Lockdown-related creativity changes were also assessed using an activitybased questionnaire, which results are consistent with those from SCC, as further discussed below.

\section{Activities carried out during the lockdown: quantitative and} qualitative aspects

We presented 28 various creative activities to our participants and assessed how those everyday creative activities were affected by the lockdown in terms of frequency, motives, encountered obstacles, and achievement. We first checked whether those activities were representative of the creative productions that individuals carried out during the lockdown by comparing them to the freely reported top-productions. Overall, $90 \%$ of the reported topproductions corresponded to activities included in our list, suggesting that our list was indeed representative. 'Home rearrangement,' 'Cooking and drinks recipes,' and 'Garden or floral arrangement' were the three activities in which participants engaged the most. In addition to being internally consistent with our self-report of top-productions, the creative activities carried out by participants were also consistent with another study that assessed the frequency of creative activities in several domains before the COVID-19 pandemic ${ }^{28}$ ('Cooking,' 'External and internal garden' and 'Creative social activity' were the three most frequent creative activities in this study ${ }^{28}$ ).

In addition, when we looked at the frequency changes in carrying out creative activities during the lockdown, we found a global quantitative increase during the lockdown. This global increase is consistent with the SCC measure showing an increase in self-perceived creativity. Qualitatively, Activities with the highest increase in frequency were 'Cooking and drinks recipes,' 'Sports program", 'Dance and choreography,' 'Mutual aid initiatives,' and 'Garden and floral arrangement.' Among them, cooking and physical training activities were 
also reported in a study conducted in New Zealand showing that individuals increased their cooking and baking activities during the lockdown ${ }^{41}$ and in another one in Italy for physical training ${ }^{42}$.

We also checked the level of creative achievement of each subject for the activities they carried out during the lockdown. We found that the score was relatively low, confirming that our questionnaire assessed 'everyday creativity' rather than extraordinary achievements. Notably, both activity-based measures, i.e., the change in creativity as measured from the activities (i.e., frequency change, Figure 1C) and the achievement score (Figure 5B), correlated with SCC, highlighting the link between subjective self-measures of creativity and real-life creative achievements.

Finally, we found a quadratic relationship between the amount of obstacles to overcome to achieve an activity and SCC: individuals who declared having a decrease in their creativity had to face too many obstacles while individuals experiencing an increase in their creativity might have been stimulated by the amount of obstacles. This result may suggest that our creative behaviors differ according to the perception of an obstacle or to the nature of the obstacle. Individual factors that influence our creative behavior in facing obstacles remain to be explored.

\section{Potential reasons for the impact of the lockdown situation on} creativity

We explored how creativity changes could be related to different factors. We found no significant effect of demographic factors on the subjective change in creativity. However, using PCA, we found that the two first principal components of the lockdown conditions and subjective experience were significantly correlated with the subjective change in creativity. The first component that we labeled 'affective change' included anxiety and stress, motivation, psychological pressure, mood, and to a lower extent, loneliness and physical constraints. This result is consistent with a series of studies showing that affective states such as positive mood and motivation are associated with higher creativity ${ }^{21,43}$, and that intrinsic motives drive everyday creative activities ${ }^{28}$. However, the impact of the situation on creativity was not positive for everybody, and some individuals reported negative changes. Negative changes could be related to negative affective states during the lockdown. Our survey shows that overall our participants reported more negative subjective and affective experiences during this period than before. This finding converges with other COVID-19 related studies conducted worldwide during the lockdown of Spring 2020 that showed that people experienced an increase in stress and depression symptoms in Italy ${ }^{4}$, Spain ${ }^{44}$, New Zealand ${ }^{45}$, Kuwait ${ }^{46}$, or Croatia ${ }^{47}$. Interestingly, we found a significant mediation effect of the principal component 1 (reflecting affective changes) on the relationships between BFI-O and SCC. This result suggests that higher openness may help to cope with difficult psychological situations during the lockdown, which in turn facilitated their self-perceived creativity 
during this period ${ }^{48}$. The second principal component of the lockdown conditions and subjective experience was related to the available time and included the number of working hours, free time, and to a lower extent, space per inhabitant. The relationship between available time and creativity has been mainly investigated in terms of time pressure hindering creativity ${ }^{49,50}$. In agreement with those previous results, we found that an increase in free time was linked to higher creativity change. An increase in free time has received less attention than affective states in lockdown-related studies, but one study mentioned that both parents and children in the Netherlands experienced having more free time during the lockdown ${ }^{51}$.

It is important to mention that given the correlational nature of the link between change in creativity and affective change, we cannot conclude about any causality effect: more positive affective states could trigger higher creativity, but the reverse could be true. Also, a third unknown variable could mediate this correlation. However, the coherence of our findings based on two different sets of measures is to be highlighted. In addition to a global subjective report of their self-perceived emotions, free time, and creativity, the participants indicated the reasons they achieved or gave up specific creative activities during the lockdown. The reasons for carrying out an activity more frequently were dominated by more free time, while the reasons for carrying out an activity less frequently were mainly related to concerns and worries. These reasons for doing or not an activity (worrying and free time) correlated with the individual component loadings of the two first principal components (reflecting affective state and free time) identified among the subjective experience factors that we collected. These results indicate consistency between the different parts of our questionnaire. Overall, the correlations of SCC with the reported affective and free time changes on the one hand, and the identified reasons for engaging more or less frequently in creative activities during the lockdown than before on the other, converge to the crucial role of emotions and free time on creativity during this period. The exact nature and context of the affective factors remain to be clarified.

\section{Limitations}

One potential limitation of our study is that our sample is not fully representative of the French population. For instance, there were more women than men in our sample, they had a high education level, and most of them could work remotely. It is also possible that individuals who participated in this survey were inherently interested in creativity or had more time for online surveys. Thus, the increase of creativity observed in this sample might not be replicable in other populations, such as individuals who could not work remotely or had no time to answer online surveys because of too heavy family issues. In addition, the participants responded just after the end of the lockdown, their reports are thus retrospective and may lack accuracy or objectivity. Yet, it is worth mentioning that most surveys used questions regarding the actual lockdown period, with difficulties in measuring a valid baseline, while in our study, we focused on the change between before and during the 
lockdown. We did not collect data during the second lockdown in France during Autumn 2020 because our survey was based on the direct assessment of changes by the subjects compared to the preceding period. As restrictions became a common situation for most individuals at the end of 2020, such an approach was not appropriate. It is possible that people experienced lassitude, and more negative affective states with the duration of the restrictions, impacting creativity more negatively than we observed during the initial period. Future studies will be needed to address this question. Finally, although our results focus on the COVID-19 related situation, they may provide interesting hypotheses to explore in future studies regarding the conditions and factors that could be acted on to foster creativity in real life.

\section{Conclusion}

The massive lockdown provoked by the COVID-19 pandemic gave an exceptional opportunity to investigate how various factors and exceptional situations could impact everyday creativity. Our study documents this unique situation regarding creativity, creativity enablers, and blockers based on the description of how individuals experienced this situation and how they adapted their everyday creative activities. While the lockdown had negative effects on affective components (such as a decrease in mood and an increase in stress and anxiety) that were associated with decreased creative self-efficacy and creative activities, it was not the most important effect on average. In fact, creativity appeared to be stimulated in a large group of individuals, potentially enabled by an increased amount of free time or opportunities that came with this unusual situation. A creative personality may have helped to cope with the negative emotions induced by the crisis, and to better express one's creativity. Those factors have thus to be considered when trying to enhance creativity in individuals and society. Future studies exploring more comprehensively the affective, emotional, and wellbeing dimensions are needed to understand better their bidirectional link with creativity during the COVID-19 related crisis.

\section{Methods}

\section{Ethics and participants}

The study was approved by the INSERM ethical committee. All the data were collected anonymously online and in compliance with the General Data Protection Regulation (GDPR). The participants were recruited online through social networks. Respondents were invited to complete the entire survey if they were French speakers over 18 years old, agreed to participate, and did not already participate.

In total, we collected data from 551 participants (365 females; mean age 42.31 years, age ranging from 18 to 84 years). Participants were French speakers and completed the survey 
between May 27 $7^{\text {th }}$ and August $1^{\text {st }}$ of the year 2020. All questions were referred to the lockdown period, that was, in mainland France, from March $16^{\text {th }}$ to May $11^{\text {th }}$ of the year 2020. Data from 171 participants were removed because they did not complete more than $50 \%$ of the survey (which corresponds to the end of part VI, see below). The final sample of the survey considered the data collected from 380 participants (281 females; mean age 43.16 years, age ranging from 18 to 84 years). All demographic details about included participants are provided in Table 1 and Supplementary Table S1.

\section{Survey and scores}

The survey was programmed in Qualtrics as a self-administered questionnaire. We collected several types of information using independent questions distributed into nine distinct parts in the following order: (I) demographic information, (II) conditions of lockdown, (III) affective experience, (IV) SCC, (V) BFI-O, (VI) the participant's behavior regarding a list of 28 activities, (VII) their ideational behavior regarding a list of three topics, (VIII) complementary information about demographics and lockdown situation, and (IX) the topcreative productions they carried out during the lockdown (written free report). We grouped those nine parts into five main types of data: demographic data, creativity-relevant measures, and potential factors linked to a change in creativity. The creative ideation part (VII) was not included in the current study, which focuses on activities instead of ideation. The types of data we collected are detailed below, indicating for each one to which part of the questionnaire the item belongs.

\section{Demographic data}

We collected individual information about participants. It includes basic demographic information (age (I), gender (I), education level (I), socio-professional activity (VIII), and main field of activity (VIII)) but also more specific information relative to the lockdown period (residential area type (II), own residence (II), country of residence (VIII), access to private or large public outdoor spaces (II), whether professional activity was COVID-19 related (II), professional situation (II), the occurrence of a serious problem that could have limited the initiation of activities (and in this case, how long it limited one's activities) (II).

\section{Measures of creativity}

We collected four different continuous variables related to participants' creativity.

The main measure was the SCC that aims to capture the self-perceived creativity change during the lockdown period. We asked participants how much they think their creativity changed positively or negatively during the lockdown as compared to before (IV). The participants responded using a continuous visual scale ranging from -50 (less creative during the lockdown) to 50 (more creative during the lockdown). 
We adapted a French-translated version of the Openness part of the Big Five Inventory (BFI$\mathrm{O})^{36}$. This is an 11 questions questionnaire that evaluates the openness personality traits of participants (V). We chose the BFI-O because openness is the personality trait most associated with creativity ${ }^{39,52}$. The participants answered each of the 11 questions using a 5-point Likert scale, converted to individual scores ranging from -2 to 2 . The BFI-O score was computed as the mean of the 11 individual responses recorded in the BFI-O.

At the end of the survey (IX), we asked participants to freely report the five most creative realizations (or top-productions) they carried out during the lockdown. They entered their responses directly in a text box without any time or word limit and with the possibility to leave empty boxes. An external panel of 5 experts in creativity research rated each of the topproductions for their creativity using a 5-point Likert scale from 0 ('not creative') to 5 ('highly creative'). Good reliability was observed between judges (ICC $=0.95$ ). Then, the ratings were averaged across judges for each top-production, and we computed for each participant a Rating Score (RS) as the sum of averaged ratings of his/her productions. The RS aims to reflect the creativity of the activities achieved during the lockdown. Hence, it may both depend on the pre-existing creativity of the participants and on the effect of the lockdown situation on their creative thinking and behavior.

In an independent part of the survey (VI), we collected information about lockdown-related changes concerning participants' involvement in creative activities. We aimed to qualitatively and quantitatively assess the creativity changes induced by the lockdown on a list of 28 creative activities (see Supplementary Table S3). The 28 activities were selected based on existing items in other validated creativity questionnaires (ICAA, CBI, and RIBS-s 37,53,54). For each activity, participants had to answer sequential questions about their involvement in this activity. The sequence of questions was conditional to their previous responses as the survey progressed (See Supplementary Figure S3 for a summary). The sequence was repeated for each of the 28 activities as follows.

For each activity, participants were first asked whether they had performed the activity during the last five years (lockdown period included). If not, the sequence stopped, and they were asked about the next activity. If so, they were asked whether they did it during the lockdown period and at which frequency ('much less,' 'less,' 'as much,' 'more', or 'much more' than before the lockdown period). They could also indicate whether they did it only during the lockdown period, i.e., if the activity was new for them. The frequency change was converted into a ranking value from -2 ('much less') to 2 ('much more'). In case the activity was not performed during the lockdown period, we assigned the value of -3 . The frequency change score was computed for each participant as the mean of these ranking values across activities. We also computed the proportion of activities for each participant for which there was a negative, a positive, or no change.

Then, for each activity reported either less or more performed during the lockdown period than before, multiple-choice questions were displayed to explore the reasons for the change 
in frequency (different options were proposed for negative and positive changes, see Supplementary Table S4) with the possibility to select several responses. Participants also had the option to write down their answers if none of the options were satisfying. We manually checked these additional reasons and created two new a posteriori categories of motives for positive changes ('Wellbeing' and 'Favorable conditions'). For each participant, and separately for positive and negative changes, we computed the number of times each reason was selected divided by the total number of activities for which the question was asked.

To check for consistency between reasons explaining changes in engaging in specific activities and the general subjective experience of the lockdown, we ran bivariate correlations between the proportions of the main activity-based selected reasons (that were related to free time and affective states) and the components of our previous PCA that related to changes in SCC (See 'Statistical analyses'). For activity-related reasons, we computed the difference in the percentage of positive and negative reasons as follows: Free time-related reasons were the difference between the proportion of 'More Time' and of 'No time.' Affective changerelated reasons were the difference in proportion between 'Inspired' and both 'Concerned and worries' / 'Did not feel like it.' The difference was computed (instead of only positive or negative) as positive and negative reasons might capture the same effect. If an individual selects 'More time' as often as 'No time' across activities (scores around zero), it might reflect a small change in experienced free time.

Finally, in case they did the activity as much or more often during the lockdown period than before, we asked:

- How they valorized it. Participants were asked to make a multiple choice among 11 options to assess the level of achievement of the performed activity. Each option represented an amount of points that reflected the level of achievement (Supplementary Table S4). Based on this question, a Creative Achievement Score was computed using a procedure similar to the ICAA scoring. The values corresponding to all the selected options for a given activity were summed. If participants shared their creative activities at least beyond the immediate surroundings (friends, family, cohabitant, or colleague), they automatically reached 8 points, and the three first proposals were not considered in the sum. Then, participant's scores were averaged across activities for each participant to compute an individual creative achievement score.

- To report their feeling of having encountered obstacles during its realization using a visual scale from 0 (no obstacles) to 100 (many obstacles). The obstacle score was computed as the mean of obstacles rating across activities for each participant.

When the series of questions related to one activity (and dependent on participant's responses) was complete, the same sequence was proposed for the next activity until the end of the list of 28 activities. 


\section{Psychological and physical conditions of confinement:} In the survey, we asked specific questions about how participants experienced the lockdown. The aim was to identify subjective and objective factors that can explain creativity changes based on our hypotheses. We collected four categories of information:

(a) Environmental conditions: we asked the participants to report the number of cohabitant and the number of available rooms in the residence place (survey part II), allowing us to compute the objective available space per cohabitant (i.e., the number of rooms per inhabitant). We also collected the subjective feeling of change in physical constraints (III).

(b) Social relationships: participants were asked whether they exchanged with as many people during the lockdown period as before (II) and the feeling of a change in loneliness (III). These variables aim to reflect changes in social relationships during the lockdown period.

(c) Available time considering the objective number of working hours per week (multiplechoice question with eight options ranging from 'not concerned' to 'more than 42 hours' with an increment of 7 hours per option) (VIII) and the feeling of a change in the amount of free time (II).

(d) Affective changes assessed by asking participants their feeling of a change in mood, motivation, anxiety, and stress, and pressure (III).

All the questions related to a change refer to a difference between the period before and during the lockdown. All subjective information in part III was collected using multiplechoice questions with eight available choices: seven ranging from 'much less' to 'much more' and one allowing a neutral response ('I do not know'). Change in free time and in social interactions had only five available choices ranging from 'much less' to 'much more.' Those variables were considered as continuous or ordinal, and the sign was reversed for the ones with a negative meaning (indicated with ' $R$ ' in figures and tables, such as loneliness) in order to obtain homogeneous valence across them (the higher, the better).

\section{Statistical analyses}

All analyses were performed using Matlab Statistical Toolbox (Matlab R2020a, The MathWorks, Inc., USA), SPSS (v22.0; IBM Corp.), and R (v3.6.2). Independent variables were defined as the reported responses by the participants (categorical variables) or as a score based on participant responses (quantitative variables; see above). Variables of interest could be binomial, ordinal, or continuous. For binomial and categorical variables (such as being a woman or a man), one-way ANOVAs were used to test their effect on continuous variables (such as SCC). Correlation analyses were performed using Pearson coefficient for continuous variables and Spearman coefficient for ordinal variables (such as Education, Frequency change in activity, and RS). When relevant, the difference from zero was tested for significance at the group level using a one-sample two-tailed t-test. 
To explore whether the relationship between RS and SCC could be mediated by creative personality traits (BFI-O), we ran a mediation analysis. The mediation analysis between SCC, BFI-O, and RS was implemented in Matlab 2020. BFI-O can be considered as a mediator if the direct path from RS to SCC is no longer significant when introducing the mediator BFI-O ( $\boldsymbol{\beta}^{*}$ SCC-RS). Thus, the mediation analysis was estimated using the two following linear models 55 :

$\mathrm{SCC}=\boldsymbol{\beta}$ sCC-RS $\times$ RS

$\mathrm{SCC}=\boldsymbol{\beta}^{*}$ SCC-RS $\times$ RS $+\boldsymbol{\beta}_{\text {SCC-BFI-O }} \times$ BFI-O

Path significance ( $\boldsymbol{\beta}_{\text {SCC-RS }}-\boldsymbol{\beta}^{*}$ SCC-RS) was then assessed with a bootstrap test using 5,000 bootsamples.

We used the same procedure to test the mediation effects of the components loadings on the link between BFI-O and SCC.

When examining the factors that can be associated with SCC during the lockdown period, we first conducted a principal component analysis to reduce the ten variables used to assess the living conditions and subjective experience of the lockdown situation into a smaller set of dimensions while retaining as much of the original information as possible. It also helped to deal with the problem of multicollinearity among our variables. We ran the principal component analysis on our ten variables of interest with oblique rotation (direct oblimin) to rotate loadings and identify the variables contributing the most to each component, using the available complete data from 287 participants. Factors with eigenvalues over Kaiser's criterion of 1 were kept. Sampling adequacy for the analysis was assessed with the KaiserMeyer-Olkin measure (standard threshold $=0.5$ ).

\section{Conflict of interest}

The authors declare no conflict of interest.

\section{Author contributions}

All authors designed the online survey and collected the data. TB, MOT, EV and ALP performed the data analyses. ALP designed the open MatLab App. ALP, TB, MOT and EV wrote the manuscript. All the authors discussed the results and commented the manuscript.

\section{Acknowledgment}

We thank all the participants to the survey. EV is funded by the 'Agence Nationale de la Recherche' [grant numbers ANR-19-CE37-001-01], the 'Fondation pour la recherche 
medicale' [grant number DEQ20150331725]. The research also received funding from the program 'Investissements d'avenir' ANR-10- IAIHU-06._MOT is funded by Becas-Chile of ANID (CONICYT)

\section{References}

1. Bu, F., Steptoe, A. \& Fancourt, D. Loneliness during a strict lockdown: Trajectories and predictors during the COVID-19 pandemic in 38,217 United Kingdom adults. Social Science \& Medicine 113521 (2020) doi:10.1016/j.socscimed.2020.113521.

2. Li, W. W., Yu, H., Miller, D. J., Yang, F. \& Rouen, C. Novelty Seeking and Mental Health in Chinese University Students Before, During, and After the COVID-19 Pandemic Lockdown: A Longitudinal Study. Front. Psychol. 11, (2020).

3. Michinov, E. \& Michinov, N. Stay at Home! When Personality Profiles Influence Psychological Adjustment and Creativity during the COVID-19 Outbreak. https://osf.io/wkhfr (2020) doi:10.31234/osf.io/wkhfr.

4. Roma, P. et al. A 2-Month Follow-Up Study of Psychological Distress among Italian People during the COVID-19 Lockdown. International Journal of Environmental Research and Public Health 17, 8180 (2020).

5. Zabelina, D., Clay, J. \& Upshaw, J. Imagination, anxiety, and loneliness during the COVID19 pandemic. (2021) doi:10.31234/osf.io/9aqbj.

6. Lubart, T., Zenasni, F. \& Barbot, B. Creative potential and its measurement. International Journal for Talent Development and Creativity 1, 41-50 (2013).

7. Lubart, T., Mouchiroud, C., Tordjman, S. \& Zenasni, F. Psychologie de la créativité - $2 e$ édition. (Armand Colin, 2015).

8. Benedek, M., Franz, F., Heene, M. \& Neubauer, A. C. Differential effects of cognitive inhibition and intelligence on creativity. Personality and Individual Differences 53, 480-485 (2012). 9. Edl, S., Benedek, M., Papousek, I., Weiss, E. M. \& Fink, A. Creativity and the Stroop interference effect. Personality and Individual Differences 69, 38-42 (2014).

10. Cassotti, M., Agogué, M., Camarda, A., Houdé, O. \& Borst, G. Inhibitory Control as a Core Process of Creative Problem Solving and Idea Generation from Childhood to Adulthood: Inhibitory Control as a Core Process of Creative Problem Solving. New Directions for Child and Adolescent Development 2016, 61-72 (2016).

11. Beaty, R. E., Christensen, A. P., Benedek, M., Silvia, P. J. \& Schacter, D. L. Creative constraints: Brain activity and network dynamics underlying semantic interference during idea production. NeuroImage 148, 189-196 (2017).

12. Mednick, S. A. The associative basis of the creative process. Psychol Rev 69, 220-232 (1962).

13. Benedek, M., Könen, T. \& Neubauer, A. C. Associative abilities underlying creativity. Psychology of Aesthetics, Creativity, and the Arts 6, 273-281 (2012).

14. Benedek, M. et al. How semantic memory structure and intelligence contribute to creative thought: a network science approach. Thinking \& Reasoning 23, 158-183 (2017).

15. Ellamil, M., Dobson, C., Beeman, M. \& Christoff, K. Evaluative and generative modes of thought during the creative process. NeuroImage 59, 1783-1794 (2012).

16. Gonen-Yaacovi, G. et al. Rostral and caudal prefrontal contribution to creativity: a metaanalysis of functional imaging data. Front. Hum. Neurosci. 7, (2013).

17. Beaty, R. E. et al. Creativity and the default network: A functional connectivity analysis of the creative brain at rest. Neuropsychologia 64, 92-98 (2014). 

5, (2014).

19. Volle, E. Associative and controlled cognition in divergent thinking: Theoretical, experimental, neuroimaging evidence, and new directions. in The Cambridge Handbook of the Neuroscience of Creativity (Editors: R.E. Jung and O. Vartanian, 2017).

20. Bendetowicz, D. et al. Two critical brain networks for generation and combination of remote associations. Brain 141, 217-233 (2018).

21. Baas, M., De Dreu, C. K. W. \& Nijstad, B. A. A meta-analysis of 25 years of mood-creativity research: Hedonic tone, activation, or regulatory focus? Psychological Bulletin 134, 779-806 (2008). 22. De Dreu, C. K. W., Baas, M. \& Nijstad, B. A. Hedonic tone and activation level in the moodcreativity link: Toward a dual pathway to creativity model. Journal of Personality and Social Psychology 94, 739-756 (2008).

861 23. Davis, M. A. Understanding the relationship between mood and creativity: A meta-analysis. Organizational Behavior and Human Decision Processes 108, 25-38 (2009).

863 24. Amabile, T. M. The social psychology of creativity: A componential conceptualization. Journal of Personality and Social Psychology 45, 357-376 (1983).

25. Amabile, T. M. \& Pillemer, J. Perspectives on the Social Psychology of Creativity. J Creat Behav 46, 3-15 (2012).

867 26. Amabile, T. M. Creativity in context: Update to the social psychology of creativity. 868 (Routledge, 2018).

869 27. Mastria, S., Agnoli, S., Zanon, M., Lubart, T. \& Corazza, G. E. Creative Brain, Creative Mind, 870 Creative Person. in Exploring Transdisciplinarity in Art and Sciences (eds. Kapoula, Z., Volle, E., Renoult, J. \& Andreatta, M.) 3-29 (Springer International Publishing, 2018). doi:10.1007/978-3-31976054-4_1.

28. Benedek, M., Bruckdorfer, R. \& Jauk, E. Motives for Creativity: Exploring the What and Why of Everyday Creativity. The Journal of Creative Behavior (2019) doi:10.1002/jocb.396.

29. Fischer, C., Malycha, C. P. \& Schafmann, E. The Influence of Intrinsic Motivation and Synergistic Extrinsic Motivators on Creativity and Innovation. Front. Psychol. 10, 137 (2019). 30. Kapoor, H. \& Kaufman, J. C. Meaning-Making Through Creativity During COVID-19. Front. Psychol. 11, (2020).

880 31. Beghetto, R. A. How Times of Crisis Serve as a Catalyst for Creative Action: An Agentic Perspective. Front. Psychol. 11, 600685 (2021). 32. Mercier, M. et al. COVID-19: A Boon or a Bane for Creativity? (2020) doi:10.31234/osf.io/c3vsr.

33. Karwowski, M. et al. Creative Lockdown? A Daily Diary Study of Creative Activity During Pandemics. Front. Psychol. 12, (2021).

885 34. Tang, C., Ma, H., Naumann, S. E. \& Xing, Z. Perceived Work Uncertainty and Creativity 886 During the COVID-19 Pandemic: The Roles of Zhongyong and Creative Self-Efficacy. Front Psychol 887 11, $596232(2020)$.

888 35. Orkibi, H. Creative Adaptability: Conceptual Framework, Measurement, and Outcomes in 889 Times of Crisis. Front. Psychol. 11, (2021).

890 36. Plaisant, O., Courtois, R., Réveillère, C., Mendelsohn, G. A. \& John, O. P. Validation par 891 analyse factorielle du Big Five Inventory français (BFI-Fr). Analyse convergente avec le NEO-PI-R. 892 Annales Médico-psychologiques, revue psychiatrique 168, 97-106 (2010).

893 37. Diedrich, J. et al. Assessment of Real-Life Creativity: The Inventory of Creative Activities 894 and Achievements (ICAA). Psychology of Aesthetics, Creativity, and the Arts (2017) 895 doi:10.1037/aca0000137.

896 38. Jauk, E., Benedek, M. \& Neubauer, A. C. The Road to Creative Achievement: A Latent 
Variable Model of Ability and Personality Predictors. Eur J Pers 28, 95-105 (2014).

39. Beaty, R. E. et al. Brain networks of the imaginative mind: Dynamic functional connectivity of default and cognitive control networks relates to openness to experience. Hum Brain Mapp (2017) doi: $10.1002 / \mathrm{hbm} .23884$.

40. Denissen, J. J. A. \& Penke, L. Motivational individual reaction norms underlying the FiveFactor model of personality: First steps towards a theory-based conceptual framework. Journal of Research in Personality 42, 1285-1302 (2008).

41. Gerritsen, S. et al. Seven weeks of home-cooked meals: changes to New Zealanders' grocery shopping, cooking and eating during the COVID-19 lockdown. Journal of the Royal Society of New Zealand 1-19 (2020) doi:10.1080/03036758.2020.1841010.

42. Di Renzo, L. et al. Eating habits and lifestyle changes during COVID-19 lockdown: an Italian survey. J Transl Med 18, 229 (2020).

43. Collins, M. A. \& Amabile, T. M. Motivation and creativity. (1999).

44. Ozamiz-Etxebarria, N., Dosil-Santamaria, M., Picaza-Gorrochategui, M. \& IdoiagaMondragon, N. Stress, anxiety, and depression levels in the initial stage of the COVID-19 outbreak in a population sample in the northern Spain. Cadernos de saude publica 36, e00054020 (2020).

45. Every-Palmer, S. et al. Psychological distress, anxiety, family violence, suicidality, and wellbeing in New Zealand during the COVID-19 lockdown: A cross-sectional study. PLoS ONE 15, e0241658 (2020).

46. Burhamah, W. et al. The psychological burden of the COVID-19 pandemic and associated lockdown measures: Experience from 4000 participants. Journal of Affective Disorders 277, 977-985 (2020).

47. Đogaš, Z. et al. The effect of COVID-19 lockdown on lifestyle and mood in Croatian general population: a cross-sectional study. Croat Med J 61, 309-318 (2020).

48. Wu, X. et al. Superior emotional regulating effects of creative cognitive reappraisal. NeuroImage (2019) doi:10.1016/j.neuroimage.2019.06.061.

49. Amabile, T. M., Conti, R., Coon, H., Lazenby, J. \& Herron, M. Assessing the work environment for creativity. Academy of management journal 39, 1154-1184 (1996).

50. Amabile, T. M. et al. Time pressure and creativity in organizations: A longitudinal field study. (2002).

51. Achterberg, M., Dobbelaar, S., Boer, O. D. \& Crone, E. A. Perceived stress as mediator for longitudinal effects of the COVID-19 lockdown on wellbeing of parents and children. Sci Rep 11, 2971 (2021).

52. Vartanian, O. et al. Structural correlates of Openness and Intellect: Implications for the contribution of personality to creativity. Hum Brain Mapp (2018) doi:10.1002/hbm.24054.

53. Runco, M. A. et al. The Incremental Validity of a Short Form of the Ideational Behavior Scale and Usefulness of Distractor, Contraindicative, and Lie Scales. J Creat Behav 48, 185-197 (2014).

54. Hocevar, D. The Development of the Creative Behavior Inventory (CBI). (1979).

55. MacKinnon, D. P. \& Dwyer, J. H. Estimating mediated effects in prevention studies. Evaluation review 17, 144-158 (1993). 


\section{Table 1}

941 Demographic data. Each information is displayed with statistical tests (one-factor ANOVA for 942 categorial factors, Spearman correlation coefficients for ordinal factors, Pearson correlation coefficients 943 for continuous factors) on SCC. SCC mean and SEM are reported in the table. N indicates the number 944 of participants in each category.

Participants

\begin{tabular}{|l|l|l|}
\hline Total included & $\begin{array}{l}\text { SCC } \\
\text { Mean }\end{array}$ & $\begin{array}{l}\text { SCC } \\
\text { SE }\end{array}$ \\
\hline 380 & 8.0 & 0.98 \\
\hline
\end{tabular}

\begin{tabular}{|l|l|l|l|l|}
\hline $\begin{array}{l}\text { Gender } \\
(\mathrm{F}(1,378)=0.01, \mathrm{p}=0.93)\end{array}$ & $\mathrm{N}$ & $\%$ & $\begin{array}{l}\text { SCC } \\
\text { Mean }\end{array}$ & $\begin{array}{l}\text { SCC } \\
\text { SE }\end{array}$ \\
\hline Female & 281 & 73.95 & 8.12 & 1.17 \\
\hline Male & 99 & 26.05 & 7.94 & 1.78 \\
\hline
\end{tabular}

\begin{tabular}{|l|l|l|l|l|}
\hline $\begin{array}{l}\text { Education } \\
(\mathrm{rho}=0.04, \mathrm{p}=0.44)\end{array}$ & N & $\%$ & $\begin{array}{l}\text { SCC } \\
\text { Mean }\end{array}$ & $\begin{array}{l}\text { SCC } \\
\text { SE }\end{array}$ \\
\hline no High School Diploma & 13 & 3.42 & 0.15 & 5.91 \\
\hline High School Diploma or Secondary Education Certificate (Baccalaureat in French) & 32 & 8.42 & 9.56 & 3.64 \\
\hline 2 or 3 years completed after High School Diploma (e.g., Bachelor's degree) & 73 & 19.21 & 7.78 & 2.17 \\
\hline 4 or 5 years completed after High School Diploma (e.g., Master's degree) & 154 & 40.53 & 7.6 & 1.61 \\
\hline more than 6 years completed after High School Diploma (e.g., Doctorate's degree) & 108 & 28.42 & 9.46 & 1.66 \\
\hline
\end{tabular}

\begin{tabular}{|c|c|c|c|c|}
\hline $\begin{array}{l}\text { Age }(\mathrm{mean}=43.16, \mathrm{SE}=15.85) \\
(\mathrm{r}=-0.02, \mathrm{p}=0.69,[\text { continuous measure }])\end{array}$ & $\mathrm{N}$ & $\%$ & $\begin{array}{l}\text { SCC } \\
\text { Mean }\end{array}$ & $\begin{array}{l}\text { SCC } \\
\text { SE }\end{array}$ \\
\hline $18-21$ & 8 & 2.11 & 5.75 & 6.08 \\
\hline $21-30$ & 97 & 25.53 & 9.98 & 1.89 \\
\hline $31-40$ & 79 & 20.79 & 6.94 & 2.22 \\
\hline $41-50$ & 66 & 17.37 & 4.73 & 2.25 \\
\hline $51-60$ & 76 & 20.00 & 11.42 & 1.98 \\
\hline $61-70$ & 30 & 7.89 & 7.63 & 4.31 \\
\hline $71+$ & 20 & 5.26 & 3.7 & 4.62 \\
\hline $\begin{array}{l}\text { Residential area } \\
(\mathrm{F}(2,377)=0.43, \mathrm{p}=0.65)\end{array}$ & $\mathrm{N}$ & $\%$ & $\begin{array}{l}\text { SCC } \\
\text { Mean }\end{array}$ & $\begin{array}{l}\text { SCC } \\
\text { SE }\end{array}$ \\
\hline Urban & 191 & 50.26 & 8.4 & 1.27 \\
\hline Peri & 128 & 33.68 & 6.92 & 1.85 \\
\hline Rural & 61 & 16.05 & 9.49 & 2.51 \\
\hline
\end{tabular}




\begin{tabular}{|l|l|l|l|l|}
\hline $\begin{array}{l}\text { Residence during confinement } \\
(\mathrm{F}(1,378)=0, \mathrm{p}=0.99)\end{array}$ & $\mathrm{N}$ & $\%$ & $\begin{array}{l}\text { SCC } \\
\text { Mean }\end{array}$ & $\begin{array}{l}\text { SCC } \\
\text { SE }\end{array}$ \\
\hline My home & 322 & 84.74 & 8.07 & 01.05 \\
\hline Other & 58 & 15.26 & 8.1 & 2.64 \\
\hline
\end{tabular}

\begin{tabular}{|l|l|l|l|l|}
\hline $\begin{array}{l}\text { Country } \\
(\mathrm{F}(5,317)=0.25, \mathrm{p}=0.94)\end{array}$ & $\mathrm{N}$ & $\%$ & $\begin{array}{l}\text { SCC } \\
\text { Mean }\end{array}$ & $\begin{array}{l}\text { SCC } \\
\text { SE }\end{array}$ \\
\hline France & 293 & 77.11 & 7.9 & 1.12 \\
\hline France-outre mer & 2 & 0.53 & 8.5 & 8.5 \\
\hline Suisse & 2 & 0.53 & 18 & 2 \\
\hline Canada & 2 & 0.53 & 2 & 8 \\
\hline Belgique & 6 & 1.58 & 8.67 & 4.2 \\
\hline Other & 18 & 4.74 & 9.67 & 4.9 \\
\hline
\end{tabular}

\begin{tabular}{|l|l|l|l|l|}
\hline $\begin{array}{l}\text { Professional Activity } \\
(\mathrm{F}(1,378)=0, \mathrm{p}=0.99)\end{array}$ & $\mathrm{N}$ & $\%$ & $\begin{array}{l}\text { SCC } \\
\text { Mean }\end{array}$ & $\begin{array}{l}\text { SCC } \\
\text { SE }\end{array}$ \\
\hline Related to the fight against COVID-19 & 43 & 11.32 & 7.86 & 3.15 \\
\hline Unrelated to the fight against COVID-19 & 315 & 82.89 & 7.87 & 1.06 \\
\hline
\end{tabular}

\section{Table 2}

947 Summary of exploratory principal component analysis results for the variables hypothetically related to creativity changes during the lockdown period $(\mathrm{n}=287)$. Loadings greater than 0.4 are in bold.

\begin{tabular}{|l|l|l|l|}
\hline & Component 1 & Component 2 & Component 3 \\
\cline { 2 - 4 } & Affective change & Available time & Interactions \\
\hline R Anxiety and stress & 0.783 & -0.023 & -0.18 \\
\hline Mood & 0.774 & 0.098 & 0.017 \\
\hline Motivation & 0.652 & 0.027 & -0.032 \\
\hline R Pressure & 0.621 & 0.383 & -0.305 \\
\hline R Loneliness & 0.594 & -0.075 & 0.295 \\
\hline R Physical constraints & 0.521 & -0.256 & 0.245 \\
\hline R Working hours & -0.161 & 0.731 & 0.138 \\
\hline Free time & 0.236 & 0.642 & -0.254 \\
\hline Space per inhabitant & -0.025 & -0.464 & -0.312 \\
\hline Social interactions & 0.042 & 0.141 & 0.831 \\
\hline Eigenvalues & 2.823 & 1.352 & 1.134 \\
\hline \% of variance & 28.227 & 13.525 & 11.341 \\
\hline
\end{tabular}




\section{Figure S1}

\section{Figure S2}

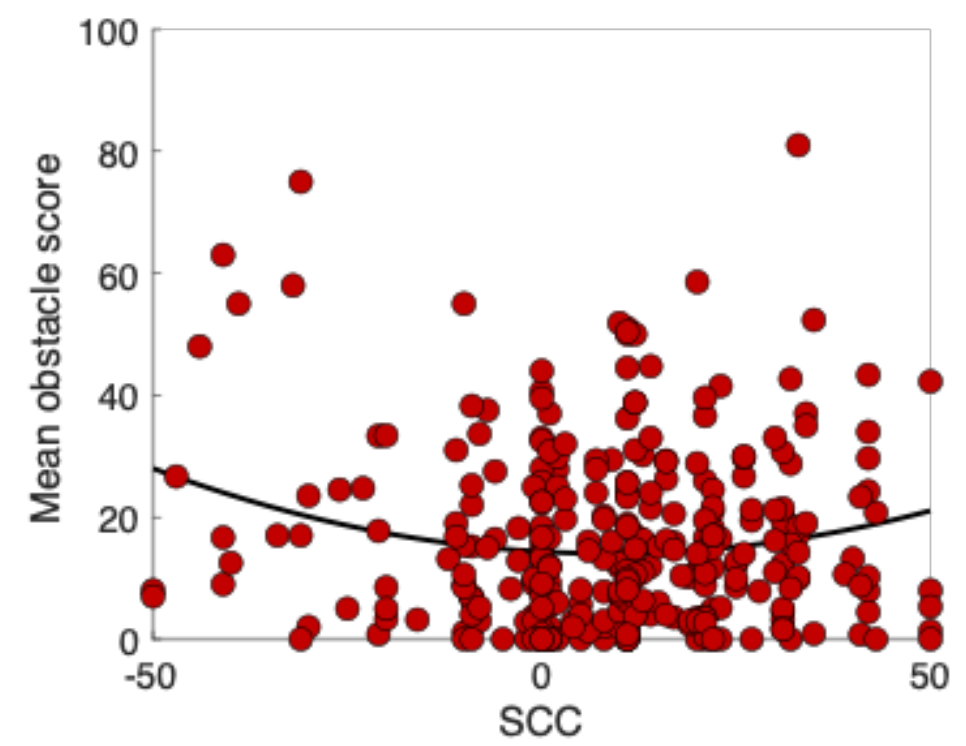
time. $(\mathrm{p}<0.05)$.
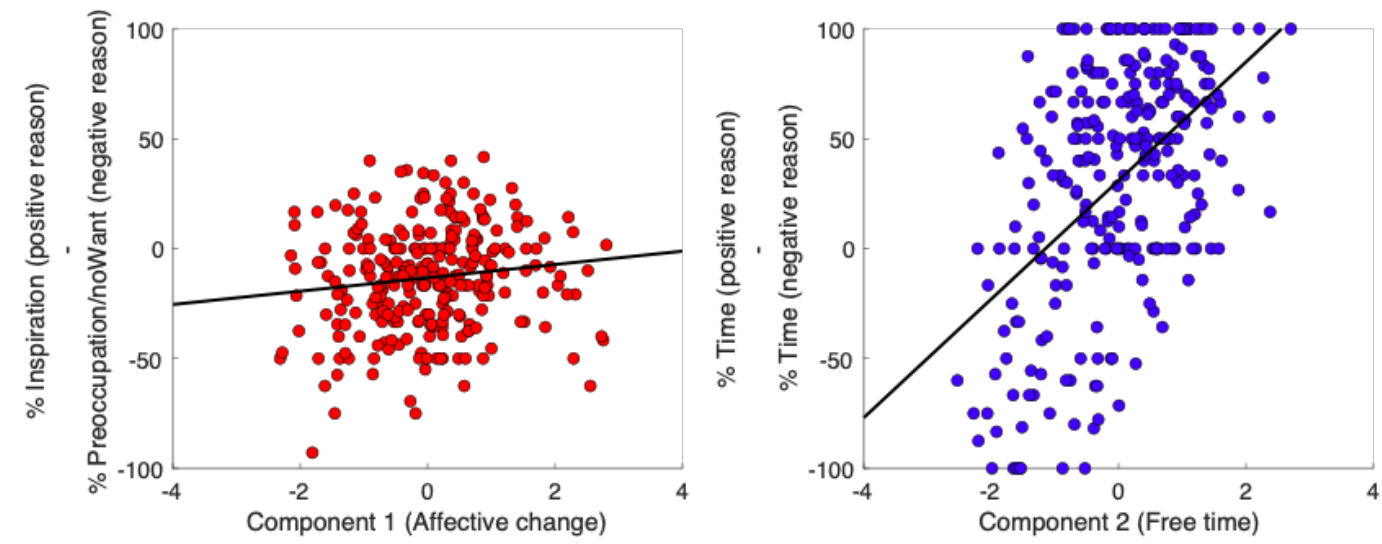

Supplementary Figure S1. Correlations between activity-based reported reasons (the difference between positive and negative reasons) and the subjective components related to creativity changes measured in the first part of the survey. Left: Proportion of 'Inspired' minus proportion of 'Concerned and worries' and 'Did not feel like it' selected respectively as positive and negative reasons for carrying out an activity per individual as a function of component loading of affective change. Right: Proportion of 'More Time' minus the proportion of 'No time' selected respectively as positive and negative reasons for carrying out an activity per individual as a function of component loading of available

Supplementary Figure S2. Individual mean obstacle score across activities as a function of individual SCC. The solid line represents a second-order polynomial fit, illustrating a significant quadratic link 


\section{Figure S3}

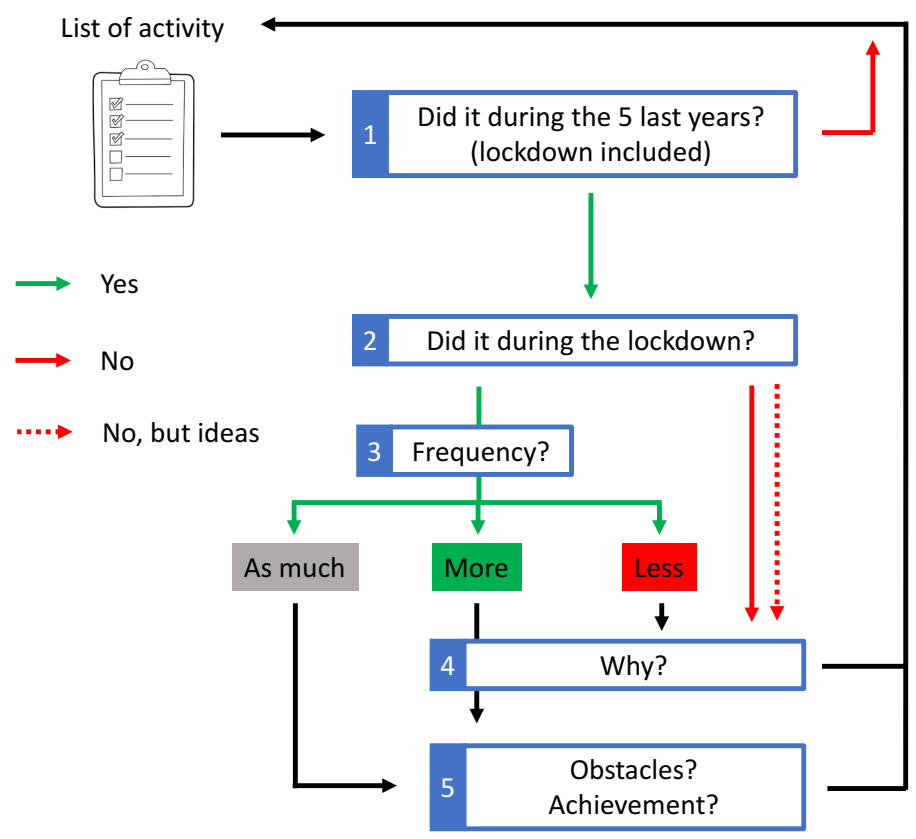

Supplementary Figure S3. Schematic representation of the conditional sequence of questions proposed for each activity

\section{Table S1}

Additional demographic information, with statistical tests (one-factor ANOVA) on SCC. SCC mean and SEM are reported in the table. $\mathrm{N}$ indicates the number of participants in each category. No statistical test was performed when one group represented less than $5 \%$ of the data (in italic).

\begin{tabular}{|c|c|c|c|c|}
\hline \multirow[t]{2}{*}{ Participants } & \multicolumn{2}{|c|}{ Total included } & $\begin{array}{l}\text { SCC } \\
\text { Mean }\end{array}$ & $\begin{array}{l}\text { SCC } \\
\text { SE }\end{array}$ \\
\hline & \multicolumn{2}{|l|}{380} & 8.0 & 0.98 \\
\hline $\begin{array}{l}\text { Professional Activity } \\
(\mathrm{F}(1,378)=0, \mathrm{p}=0.99)\end{array}$ & $\mathrm{N}$ & $\%$ & $\begin{array}{l}\text { SCC } \\
\text { Mean }\end{array}$ & $\begin{array}{l}\text { SCC } \\
\text { SE }\end{array}$ \\
\hline Related to the fight against COVID-19 & 43 & 11.32 & 7.86 & 3.15 \\
\hline Unrelated to the fight against COVID-19 & 315 & 82.89 & 7.87 & 1.06 \\
\hline $\begin{array}{l}\text { Socio-professional category } \\
(\mathrm{F}(8,350)=1.45, \mathrm{p}=0.17)\end{array}$ & $\mathrm{N}$ & $\%$ & $\begin{array}{l}\text { SCC } \\
\text { Mean }\end{array}$ & $\begin{array}{l}\text { SCC } \\
\text { SE }\end{array}$ \\
\hline Agriculture/Operator & 2 & 0.53 & 17 & 17 \\
\hline Artisan/ Merchant/Entrepreneur & 4 & 01.05 & 12 & 15.95 \\
\hline Professionals and intellectual professions & 162 & 42.63 & 8.44 & 1.37 \\
\hline Intermediate professions & 28 & 7.37 & 09.07 & 3.66 \\
\hline Employee & 49 & 12.89 & 11.88 & 2.6 \\
\hline Student & 43 & 11.32 & 6.93 & 2.7 \\
\hline
\end{tabular}




\begin{tabular}{|l|l|l|l|l|}
\hline Salaried worker & 1 & 0.26 & 33 & 0 \\
\hline Retired & 33 & 8.68 & 5.62 & 2.95 \\
\hline Other & 37 & 9.74 & -0.3 & 4.64 \\
\hline
\end{tabular}

\begin{tabular}{|c|c|c|c|c|}
\hline $\begin{array}{l}\text { Main field of activity } \\
(\mathrm{F}(19,339)=0.64, \mathrm{p}=0.88)\end{array}$ & $\mathrm{N}$ & $\%$ & $\begin{array}{l}\text { SCC } \\
\text { Mean }\end{array}$ & $\begin{array}{l}\text { SCC } \\
\text { SE }\end{array}$ \\
\hline Agriculture / Agronomy & 3 & 0.79 & 15 & 10.02 \\
\hline Arts/ Design/ Architecture & 29 & 7.63 & 5.97 & 5.09 \\
\hline Audiovisual / Cinema / Spectacle/ Musician & 11 & 2.89 & 5.45 & 5.4 \\
\hline Audit / Accounting & 8 & 2.11 & 7.75 & 7.09 \\
\hline Building / public worker & 2 & 0.53 & 6.5 & 6.5 \\
\hline Food trade / Distribution & 1 & 0.26 & 20 & 0 \\
\hline Non - food retail / Distribution & 6 & 1.58 & 0.17 & 11.4 \\
\hline Culture / Artisan & 13 & 3.42 & 2.54 & 7.11 \\
\hline Law/ Justice/ Economy / Management & 9 & 2.37 & 18.11 & 6.2 \\
\hline Education & 25 & 6.58 & 10.04 & 3.51 \\
\hline Finance/ Bank/ Insurance & 12 & 3.16 & 5.58 & 7.03 \\
\hline Industry & 6 & 1.58 & 9.83 & 9.67 \\
\hline Computer science / Engineering & 28 & 7.37 & 3.29 & 2.65 \\
\hline Medias/ Communication / Marketing / Advertising & 17 & 4.47 & 14.53 & 3.79 \\
\hline Research / Higher Education & 69 & 18.16 & 8.46 & 1.97 \\
\hline Health & 70 & 18.42 & 8.46 & 2.27 \\
\hline Security & 0 & 0 & - & - \\
\hline Social & 21 & 5.53 & 7.48 & 3.76 \\
\hline Sports / Leisure & 6 & 1.58 & 4.17 & 11.93 \\
\hline Tourism / Hotel / Restoration & 3 & 0.79 & 9.67 & 6.33 \\
\hline Transportation & 0 & 0 & - & - \\
\hline Other & 20 & 5.26 & 9.1 & 3.16 \\
\hline
\end{tabular}

\begin{tabular}{|l|l|l|l|l|l|}
\hline \multicolumn{2}{|l|}{ Professional situation during confinement } & $\mathrm{N}$ & $\%$ & $\begin{array}{l}\text { SCC } \\
\text { Mean }\end{array}$ & $\begin{array}{l}\text { SCC } \\
\text { SE }\end{array}$ \\
\hline $\begin{array}{l}\text { I kept moving to my workplace } \\
(\mathrm{F}(1,356)=0.77, \mathrm{p}=0.38)\end{array}$ & Yes & 54 & 14.21 & 5.76 & 2.56 \\
\cline { 2 - 7 } & No & 304 & 80.00 & 8.24 & 1.1 \\
\hline $\begin{array}{l}\text { Remote working } \\
(\mathrm{F}(1,356)=0.56, \mathrm{p}=0.46)\end{array}$ & Yes & 204 & 53.68 & 8.52 & 1.25 \\
\cline { 2 - 7 } & No & 154 & 40.53 & 7 & 1.66 \\
\hline $\begin{array}{l}\text { Partial unemployment } \\
(\mathrm{F}(1,356)=1.32, \mathrm{p}=0.25)\end{array}$ & Yes & 49 & 12.89 & 10.78 & 2.92 \\
\cline { 2 - 7 } Searching for a job & No & 309 & 81.32 & 7.4 & 1.07 \\
\hline$(\mathrm{F}(1,356)=0.8, \mathrm{p}=0.37)$ & Yes & 31 & 8.16 & 4.94 & 4.02 \\
\cline { 2 - 7 } & No & 327 & 86.05 & 8.14 & 1.04 \\
\hline & Yes & 41 & 10.79 & 5.83 & 3.15 \\
\hline
\end{tabular}




\begin{tabular}{|l|l|l|l|l|l|}
\hline $\begin{array}{l}\text { Student } \\
(\mathrm{F}(1,356)=0.53, \mathrm{p}=0.47)\end{array}$ & No & 317 & 83.42 & 8.13 & 1.06 \\
\hline \multirow{2}{*}{ House-husband / housewife } & Yes & 12 & 3.16 & 11.58 & 7.5 \\
\cline { 2 - 7 } & No & 346 & 91.05 & 7.74 & 1.01 \\
\hline \multirow{2}{*}{$\begin{array}{l}\text { Retired } \\
(\mathrm{F}(1,356)=0.78, \mathrm{p}=0.38)\end{array}$} & Yes & 41 & 10.79 & 5.39 & 3.03 \\
\cline { 2 - 7 } & No & 317 & 83.42 & 8.19 & 1.07 \\
\hline \multirow{2}{*}{ On sick leave } & Yes & 10 & 2.63 & 24.4 & 7.21 \\
\cline { 2 - 7 } & No & 348 & 91.58 & 7.39 & 1.01 \\
\hline \multirow{2}{*}{ Maternity / paternity leave } & Yes & 2 & 0.53 & 26.5 & 10.5 \\
\cline { 2 - 7 } & No & 356 & 93.68 & 7.76 & 1.01 \\
\hline
\end{tabular}

977 Pearson correlation coefficients and p-values between SCC and living conditions / subjective 978 experience of the lockdown situation. N indicate the number of participants included (available data).

\begin{tabular}{|l|l|l|l|}
\hline & Pearson correlation coefficients with SCC & p-value (2-tailed) & $\mathrm{N}$ \\
\hline R Anxiety and stress & 0.175 & 0.001 & 380 \\
\hline Mood & 0.226 & $<0.001$ & 380 \\
\hline Motivation & 0.462 & $<0.001$ & 380 \\
\hline R Pressure & 0.185 & $<0.001$ & 380 \\
\hline R Loneliness & 0.088 & 0.086 & 380 \\
\hline R Physical constraints & 0.092 & 0.075 & 380 \\
\hline R Working hours & -0.013 & 0.796 & 287 \\
\hline Free time & 0.147 & 0.004 & 380 \\
\hline Space per inhabitant & -0.069 & 0.242 & 380 \\
\hline Social interactions & 0.079 & 0.125 & 380 \\
\hline
\end{tabular}


982 List of the 28 activities for which participants had to respond a series of question. Original French sentence, English translation and short name are reported for each of the activity.

\begin{tabular}{|c|c|c|c|}
\hline Activity & French & English translation & Short name \\
\hline 1 & J'ai fabriqué un meuble & I made a piece of furniture & Furniture making \\
\hline 2 & $\begin{array}{l}\text { J'ai créé une décoration pour mon } \\
\text { habitation }\end{array}$ & I created a decoration for my home & Decoration creation \\
\hline 3 & $\begin{array}{l}\text { J'ai organisé ou réorganisé une } \\
\text { pièce de mon habitation }\end{array}$ & $\begin{array}{l}\text { I have organized or reorganized a } \\
\text { room in my home }\end{array}$ & $\begin{array}{l}\text { Home } \\
\text { rearrangement }\end{array}$ \\
\hline 4 & $\begin{array}{l}\text { J'ai entrepris du jardinage ou réalisé une } \\
\text { composition florale }\end{array}$ & $\begin{array}{l}\text { I started gardening or made a flower } \\
\text { arrangement }\end{array}$ & $\begin{array}{l}\text { Garden or floral } \\
\text { arrangement }\end{array}$ \\
\hline 5 & J'ai réparé seul un objet cassé & I repaired a broken object alone & Object repair \\
\hline 6 & J'ai conçu un bijou & I designed some jewelry & Jewelry design \\
\hline 7 & $\begin{array}{l}\text { J'ai conçu ou revisité un vêtement ou un } \\
\text { accessoire (couture, tricot, ...) }\end{array}$ & $\begin{array}{l}\text { I have designed or revisited an item } \\
\text { of clothing or an accessory (sewing, } \\
\text { knitting, ...) }\end{array}$ & $\begin{array}{ll}\text { Clothing } & \text { or } \\
\text { accessories } & \end{array} \mid$ \\
\hline 8 & $\begin{array}{l}\text { J'ai recyclé ou détourné un objet } \\
\text { (non mentionné plus tôt) pour lui donner } \\
\text { une deuxième vie }\end{array}$ & $\begin{array}{l}\text { I recycled or diverted the use of an } \\
\text { object (not mentioned previously) to } \\
\text { give it a second life }\end{array}$ & $\begin{array}{l}\text { Recycling } \quad \text { and } \\
\text { alternative use of } \\
\text { objects }\end{array}$ \\
\hline 9 & $\begin{array}{l}\text { J'ai conçu ou revisité une recette } \\
\text { de cuisine, une boisson ou un cocktail }\end{array}$ & $\begin{array}{l}\text { I designed or revisited a cooking } \\
\text { recipe, a drink or a cocktail }\end{array}$ & $\begin{array}{l}\text { Cooking and drink } \\
\text { recipes }\end{array}$ \\
\hline 10 & $\begin{array}{l}\text { J'ai mis en place des jeux ludiques et/ou } \\
\text { pédagogiques pour des enfants (loisirs ou } \\
\text { école à la maison) }\end{array}$ & $\begin{array}{l}\text { I have set up fun and / or educational } \\
\text { games for children (leisure or home } \\
\text { school) }\end{array}$ & $\begin{array}{lr}\text { Games } & \text { and } \\
\text { education } & \text { for } \\
\text { children } & \end{array}$ \\
\hline 11 & $\begin{array}{l}\text { J'ai inventé ou organisé un jeu, un quizz ou } \\
\text { un concours (pour des amis, famille, } \\
\text { collègues...) }\end{array}$ & $\begin{array}{l}\text { I invented or organized a game, a } \\
\text { quiz or a contest (for friends, family, } \\
\text { colleagues ...) }\end{array}$ & $\begin{array}{l}\text { Games or contests } \\
\text { for adults }\end{array}$ \\
\hline 12 & $\begin{array}{l}\text { J'ai élaboré un programme ou un } \\
\text { exercice d'entraînement sportif }\end{array}$ & $\begin{array}{l}\text { I have developed a sports training } \\
\text { program or exercise }\end{array}$ & Sports program \\
\hline 13 & $\begin{array}{l}\text { J'ai réalisé un tableau, un dessin } \\
\text { ou un collage original }\end{array}$ & $\begin{array}{l}\text { I made an original painting, drawing } \\
\text { or collage }\end{array}$ & $\begin{array}{l}\text { Original painting, } \\
\text { drawing or collage }\end{array}$ \\
\hline 14 & $\begin{array}{l}\text { J'ai réalisé une sculpture, une mosaïque, } \\
\text { une poterie ou de la céramique }\end{array}$ & $\begin{array}{l}\text { I made a sculpture, a mosaic, a } \\
\text { pottery or a ceramic }\end{array}$ & $\begin{array}{l}\text { Original sculpture } \\
\text { or alike }\end{array}$ \\
\hline 15 & J'ai créé un slogan ou un logo & I created a slogan or logo & Logo creation \\
\hline 16 & $\begin{array}{l}\text { J'ai réalisé ou j'ai joué dans une } \\
\text { vidéo, un montage, un court ou long- } \\
\text { métrage, ou un film d'animation }\end{array}$ & $\begin{array}{l}\text { I made or acted in a video, a } \\
\text { montage, a short or full-length film, } \\
\text { or an animation film }\end{array}$ & Films and videos \\
\hline 17 & $\begin{array}{l}\text { J'ai réalisé des images photographiques } \\
\text { avec des techniques originales }\end{array}$ & $\begin{array}{l}\text { I made photographic images with } \\
\text { original techniques }\end{array}$ & Photography \\
\hline 18 & $\begin{array}{l}\text { J'ai écrit une histoire, un poème, } \\
\text { une nouvelle, un roman, une bande } \\
\text { dessinée, ou une pièce de théâtre }\end{array}$ & $\begin{array}{l}\text { I wrote a story, a poem, a short story, } \\
\text { a novel, a comic book, or a play }\end{array}$ & $\begin{array}{l}\text { Short or long } \\
\text { literary writing }\end{array}$ \\
\hline
\end{tabular}




\begin{tabular}{|c|c|c|c|}
\hline 19 & J'ai écrit un article & I wrote an article & Article writing \\
\hline 20 & $\begin{array}{l}\text { J'ai inventé ou revisité une musique, une } \\
\text { mélodie, un rythme ou les paroles d'une } \\
\text { chanson }\end{array}$ & $\begin{array}{l}\text { I invented or revisited a music, a } \\
\text { melody, a rhythm or the lyrics of a } \\
\text { song }\end{array}$ & Music and lyrics \\
\hline 21 & $\begin{array}{l}\text { J'ai conçu un instrument de musique ou } \\
\text { une manière de faire de la musique }\end{array}$ & $\begin{array}{l}\text { I designed a musical instrument or } \\
\text { invented a way to make music }\end{array}$ & Musical instrument \\
\hline 22 & $\begin{array}{l}\text { J'ai inventé ou ré-interprété une } \\
\text { chorégraphie ou une danse }\end{array}$ & $\begin{array}{l}\text { I invented or re-interpreted a } \\
\text { choreography or a dance }\end{array}$ & $\begin{array}{ll}\text { Dance } & \text { and } \\
\text { choreography } & \end{array}$ \\
\hline 23 & $\begin{array}{l}\text { J'ai conçu un programme informatique, un } \\
\text { site internet ou une enquête }\end{array}$ & $\begin{array}{l}\text { I designed a computer program, a } \\
\text { website or a survey }\end{array}$ & $\begin{array}{l}\text { Website, survey or } \\
\text { computer program }\end{array}$ \\
\hline 24 & $\begin{array}{l}\text { J'ai créé un tutoriel ou un cours } \\
\text { (hors sport et éducation des enfants) }\end{array}$ & $\begin{array}{l}\text { I created a tutorial or a course } \\
\text { (excluding sports and children's } \\
\text { education) }\end{array}$ & $\begin{array}{l}\text { Courses } \\
\text { tutorials }\end{array}$ \\
\hline 25 & $\begin{array}{l}\text { J'ai créé ou organisé un système ou réseau } \\
\text { d'entraide (par exemple de distribution de } \\
\text { nourriture ou de soutien aux personnes } \\
\text { isolées) }\end{array}$ & $\begin{array}{l}\text { I have created or organized a support } \\
\text { system or network (for example for } \\
\text { the distribution of food or support } \\
\text { for isolated people) }\end{array}$ & $\begin{array}{l}\text { Mutual } \\
\text { initiatives }\end{array}$ \\
\hline 26 & $\begin{array}{l}\text { J'ai organisé de manière originale un } \\
\text { événement (anniversaire, apéritif, ...) ou } \\
\text { inventé des solutions alternatives pour } \\
\text { échanger avec les autres (club, lettres, ...) }\end{array}$ & $\begin{array}{l}\text { I organized an event in an original } \\
\text { way (birthday, aperitif, ...) or } \\
\text { invented alternative solutions to } \\
\text { communicate with others (club, } \\
\text { letters, ...) }\end{array}$ & $\begin{array}{l}\text { Event organization } \\
\text { and communication }\end{array}$ \\
\hline 27 & J'ai fabriqué un objet ou un accessoire & I made an object or an accessory & Object making, craft \\
\hline 28 & $\begin{array}{l}\text { J'ai écrit un projet innovant ou diversifié } \\
\text { mon activité dans le cadre de mon travail }\end{array}$ & $\begin{array}{l}\text { I wrote an innovative project or } \\
\text { diversified my activity as part of my } \\
\text { work }\end{array}$ & Professional project \\
\hline
\end{tabular}


987 Details of the presented options for reasons for change in the frequency of an activity, and details of the presented options of achievement reached for each activity. Original French sentence, English translation and short name are detailed. Ranking values were used to compute the achievement score.

\begin{tabular}{|c|c|c|c|c|}
\hline & French & English translation & Short name & $\begin{array}{l}\text { Ranking } \\
\text { value }\end{array}$ \\
\hline \multirow{7}{*}{ 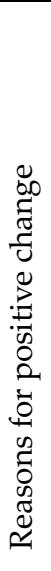 } & J'avais plus de temps & I had more time & More time & - \\
\hline & $\begin{array}{l}\text { Le confinement et/ou l'épidémie m'ont } \\
\text { inspiré.e }\end{array}$ & The situation inspired me & Inspired & - \\
\hline & $\begin{array}{l}\text { Je devais résoudre un problème lié au } \\
\text { confinement ou à l'épidémie de COVID-19 }\end{array}$ & $\begin{array}{l}\text { I had to solve a problem } \\
\text { related to the situation }\end{array}$ & Problem solving & - \\
\hline & Je devais le faire pour mon travail & I had to do it for work & Work related & - \\
\hline & Autres & Others & Others & - \\
\hline & Je l'ai fait pour me sentir mieux & I did it to feel better & Wellbeing & - \\
\hline & $\begin{array}{l}\text { J'étais dans des conditions favorable pour le } \\
\text { faire }\end{array}$ & $\begin{array}{l}\text { I was in favorable } \\
\text { conditions to do it }\end{array}$ & $\begin{array}{l}\text { Favorable } \\
\text { conditions }\end{array}$ & - \\
\hline \multirow{8}{*}{ 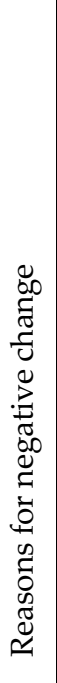 } & Je n'ai pas eu le temps & I had no time to do it & No time & - \\
\hline & J'avais d'autre soucis ou préoccupations & I had other concerns & $\begin{array}{l}\text { Concerns and } \\
\text { worries }\end{array}$ & - \\
\hline & $\begin{array}{l}\text { Mes conditions de confinement ne m'ont pas } \\
\text { permis de le faire }\end{array}$ & $\begin{array}{l}\text { I was not in favorable } \\
\text { conditions to do it }\end{array}$ & $\begin{array}{l}\text { Unfavorable } \\
\text { conditions }\end{array}$ & - \\
\hline & $\begin{array}{l}\text { Je n'avais pas les ressources matérielles } \\
\text { nécessaires }\end{array}$ & $\begin{array}{l}\text { I did not have the material } \\
\text { opportunities to do it }\end{array}$ & Lack of resources & - \\
\hline & Je n'ai pas eu envie & I did not feel like it & Did not feel like it & - \\
\hline & Les idées ne me venaient plus & I hadn't any ideas & Lack of ideas & - \\
\hline & $\begin{array}{l}\text { Je ne l'avais fait que ponctuellement } \\
\text { auparavant }\end{array}$ & $\begin{array}{l}\text { I did it only a few times } \\
\text { before }\end{array}$ & Occasionally & - \\
\hline & Autres & Others & Others & - \\
\hline \multirow{7}{*}{ 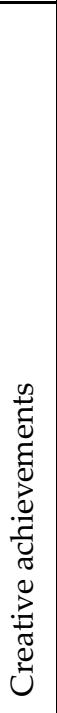 } & Je ne l'ai montré à personne & I did not share it & Not shared & 2 \\
\hline & Je l'ai montré à mes co-confinés & $\begin{array}{l}\text { I shared it with my co- } \\
\text { confinees }\end{array}$ & $\begin{array}{l}\text { Shared with co- } \\
\text { confinees }\end{array}$ & 3 \\
\hline & $\begin{array}{l}\text { Je l'ai montré à mes amis, mes proches ou mes } \\
\text { collègues }\end{array}$ & $\begin{array}{l}\text { I shared it with my close } \\
\text { ones }\end{array}$ & $\begin{array}{l}\text { Shared with close } \\
\text { ones }\end{array}$ & 3 \\
\hline & $\begin{array}{l}\text { Je l'ai montré à des inconnus au-delà de mon } \\
\text { cercle habituel ou sur les réseaux sociaux }\end{array}$ & $\begin{array}{l}\text { I shared it with my remote } \\
\text { ones }\end{array}$ & $\begin{array}{l}\text { Shared with } \\
\text { remote ones }\end{array}$ & 4 \\
\hline & $\begin{array}{l}\text { Cela a été remarqué par des personnes au- } \\
\text { delà de mon cercle habituel ou sur les réseaux } \\
\text { sociaux }\end{array}$ & $\begin{array}{l}\text { It was noticed on social } \\
\text { networks }\end{array}$ & $\begin{array}{l}\text { Noticed on social } \\
\text { networks }\end{array}$ & 4 \\
\hline & Les médias en ont parlé & The media talked about it & $\begin{array}{l}\text { Noticed on the } \\
\text { media }\end{array}$ & 9 \\
\hline & Je l'ai publié & It was published & Published & 6 \\
\hline
\end{tabular}




\begin{tabular}{|l|l|l|l|} 
Cela m'a permis de participer à un concours & $\begin{array}{l}\text { I participated in a } \\
\text { competition }\end{array}$ & $\begin{array}{l}\text { Participated in a } \\
\text { competition }\end{array}$ & 7 \\
$\begin{array}{l}\text { Cela m'a permis de gagner une récompense } \\
\text { ou un prix }\end{array}$ & $\begin{array}{l}\text { I won a competition or a } \\
\text { price }\end{array}$ & $\begin{array}{l}\text { Won a } \\
\text { competition or a } \\
\text { price }\end{array}$ & 8 \\
$\begin{array}{l}\text { J'ai réussi à le vendre } \\
\text { Autre proposition }\end{array}$ & It was sold & Sold & 10 \\
\hline
\end{tabular}

991 